\title{
Low-Intensity Training and the C5a Complement Antagonist NOX-D21 Rescue the $m d x$ Phenotype through Modulation of Inflammation
}

Janek Hyzewicz, ${ }^{*}$ Jun Tanihata, ${ }^{*}$ Mutsuki Kuraoka, ${ }^{*}$ Yuko Nitahara-Kasahara, ${ }^{*}$ Teiva Beylier, ${ }^{*}$ Urs T. Ruegg, ${ }^{\dagger}$ Axel Vater, ${ }^{\ddagger}$ and Shin'ichi Takeda*

From the Department of Molecular Therapy, * National Institute of Neuroscience, National Centre of Neurology and Psychiatry, Tokyo, Japan; the Laboratory of Pharmacology, ${ }^{\dagger}$ University of Geneva, Geneva, Switzerland; and Drug Discovery and Preclinical Development ${ }^{\ddagger}$ NOXXON Pharma, Berlin, Germany

Accepted for publication December 27, 2016.

Address correspondence to Shin'ichi Takeda, M.D., Ph.D., Department of Molecular Therapy, National Institute of Neuroscience, National Center of Neurology and Psychiatry, 4-1-1 Ogawa-Higashi, Kodaira, Tokyo 187-8502, Japan. E-mail: takeda@ncnp.go.jp.

\begin{abstract}
Inflammatory events occurring in dystrophic muscles contribute to the progression of Duchenne muscular dystrophy (DMD). Low-intensity training (LIT) attenuates the phenotype of $m d x$ mice, an animal model for DMD. Therefore, we postulated that LIT could have anti-inflammatory properties. We assessed levels of inflammatory cytokines and infiltrated immune cells in gastrocnemius muscle of $m d x$ mice after LIT. We detected high levels of complement component C5a, chemokine ligand (CCL) 2, $\mathrm{CD}^{+} 8^{+}$monocytes/macrophages, and proinflammatory M1 macrophages in muscles of $m d x$ mice. LIT decreased CCL2 levels, increased $\mathrm{CD} 68^{+}$cell numbers, and shifted the macrophage population to the regenerative M2 type. We investigated whether inhibition of $\mathrm{C} 5 \mathrm{a}$ or $\mathrm{CCL} 2$ with L-aptamers could mimic the effects of LIT. Although no effect of CCL2 inhibition was detected, treatment with the C5a inhibitor, NOX-D21, rescued the phenotype of nonexercised $m d x$ mice, but not of exercised ones. In both cases, the level of $\mathrm{CD}_{68}{ }^{+}$cells increased and macrophage populations leaned toward the inflammatory M1 type. In muscles of nonexercised treated mice, the level of IL-1 receptor antagonist increased, damage decreased, and fibers were switched toward the glycolytic fast type; in muscles of exercised mice, fibers were switched to the oxidative slow type. These results reveal the effects of LIT on the inflammatory status of $m d x$ mice and suggest that NOX-D21 could be an anti-inflammatory drug for DMD. (Am J Pathol 2017, 187: 1147-1161; http://dx.doi.org/10.1016/j.ajpath.2016.12.019)
\end{abstract}

Duchenne muscular dystrophy (DMD) is a lethal congenital neuromuscular disease caused by mutations in the $D M D$ gene. A lack of dystrophin in skeletal muscle of DMD patients results in altered mechanical and signaling functions that contribute to membrane fragility, necrosis of muscle fibers, inflammation, and progressive muscle wasting. ${ }^{1,2}$

Immune cells infiltrate into dystrophic muscles during the early stage of the disease and contribute substantially to the onset and the progression of DMD. The muscular dystrophy, X-linked mouse model $(m d x)$, has a point mutation in the dystrophin gene causing dystrophin deficiency; it is an established and most often used animal model for DMD. Immune cell infiltration begins at an age of 2 weeks, peaks around 4 to 8 weeks, and then decreases in severity by 3 months of age. ${ }^{3}$ Myeloid cells $\left(\mathrm{CD} 11 \mathrm{~b}^{+}\right)$of the monocyte/ macrophage lineage $\left(\mathrm{CD}^{+} 8^{+}\right)$are the principal infiltrating population and accumulate in muscle at approximately 80,000 cells $/ \mathrm{mm}^{3}$ of tissue. ${ }^{4,5}$ In comparison, the second most important population, the $\mathrm{T}$ cells, infiltrate to a level of approximately 1200 cells $/ \mathrm{mm}^{3}{ }^{3}$. Differentiated macrophages $\left(\mathrm{F} 4 / 80^{+}\right)$are divided by functional criteria into two subpopulations, namely proinflammatory M1 [inducible nitric oxide synthase (iNOS) ${ }^{+}$] and anti-inflammatory M2 $\left(\mathrm{CD} 163^{+}, \mathrm{CD}^{206^{+}}\right)$macrophages. ${ }^{7}$ In muscles of $m d x$ mice as well as DMD patients, ${ }^{1}$ the balance between M1 and M2

\footnotetext{
Supported by National Center of Neurology and Psychiatry intramural research grants 25-5 and 28-6 for Neurological and Psychiatric Disorders (S.T.).

Disclosures: A.V. is an employee of NOXXON Pharma, which provided the L-aptamers NOX-D21 and NOX-E36m; he holds $<1 \%$ of the shares of this company.
} 
populations leans in favor of the M1 population, promoting muscle injury. ${ }^{8}$

Physical exercise has been shown to generate an antiinflammatory environment. ${ }^{9}$ Previous studies demonstrated that appropriate training reduces the inflammation in muscles of patients with idiopathic inflammatory myopathies. ${ }^{10}$ Chronic running also inhibits macrophage infiltration into inflamed tissues and promotes a phenotypic switch from the M1 to the M2 population in murine models characterized by an abnormal inflammation, such as the high-fat dietinduced obese mice. ${ }^{11}$ Yet, the effect of training on the inflammatory status of dystrophic muscles has never been assessed in DMD patients and has given mixed results in $m d x$ mice, as described below.

Physical exercise can be either beneficial or detrimental to $m d x$ mice, depending on the age of the animals and the intensity of training. ${ }^{12}$ Low-intensity training (LIT), such as voluntary running or swimming of $m d x$ mice, improves muscle force and endurance, ${ }^{13,14}$ and increases the expression of mitochondrial proteins. ${ }^{15,16}$ High-intensity training, such as forced treadmill or downhill running of $m d x$ mice, causes loss of force and necrosis ${ }^{17,18}$ as well as fibrosis. ${ }^{19}$ High-intensity training of $m d x$ mice also worsens their inflammatory status, leading to increased mRNA expression for IL- $1 \beta$ and IL- $6{ }^{17}$ decreased mRNA expression for insulin-like growth factor $1^{20}$ and tumor necrosis factor- $\alpha,{ }^{18}$ and increased protein expression of transforming growth factor- $\beta 1$ in muscles. ${ }^{19}$

We postulated that LIT reduces the expression of proinflammatory factors in $m d x$ skeletal muscle, resulting in a reduction of macrophage infiltration and a phenotypic switch from the M1 to M2 macrophage population. To test this hypothesis, we immunoblotted and stained sections from the gastrocnemius muscles of 8-week-old $m d x$ mice. We found an overexpression of chemokine ligand (CCL) 2 and of the complement component $\mathrm{C} 5 \mathrm{a}$, a high number of $\mathrm{CD}^{+} 8^{+}$cells, and a dominance of M1 macrophages in nonexercised $m d x$ muscle. Four weeks of LIT decreased the levels of CCL2, shifted the macrophage population to the M2 subtype, but further increased the number of $\mathrm{CD} 68^{+}$cells, which are $\mathrm{F} 4 / 80^{+}$ mature macrophages. The level of C5a was unchanged.

In a second step, we assessed the effects of inhibitors of CCL2 and C5a, mNOX-E36 and NOX-D21, respectively. Although no effect was detected from mNOX-E36 treatment, NOX-D21 rescued the phenotype of nonexercised $m d x$ mice, but not of exercised ones. Numbers of $\mathrm{CD} 68^{+}$ cells and M1 macrophages increased in both groups; however, only nonexercised $m d x$ mice presented an increased IL-1 receptor antagonist (IL-RA) level, reduction of muscle damage, and a switch to glycolytic, fast-type muscle fibers.

\section{Materials and Methods}

\section{Animals}

Groups of four to five 8-week-old male $m d x$ mice with C57BL/6 background or age-matched wild-type C57BL/6 male control mice were used in this study. All experimental protocols were approved by The Experimental Animal Care and Use Committee of the National Institute of Neuroscience, National Center of Neurology and Psychiatry (Tokyo, Japan).

\section{Low-Intensity Training Protocol}

Mice underwent training when they reached 4 weeks of age. According to a previously published protocol, ${ }^{16}$ mice were introduced into a tank $(40 \times 25 \times 20 \mathrm{~cm})$ filled with water (maintained at $35^{\circ} \mathrm{C} \pm 1^{\circ} \mathrm{C}$ ) to a depth enough to force them to swim. Animals underwent a 4-week program in which they exercised for 30 minutes 4 days in a week (Monday, Tuesday, Thursday, and Friday), whereas they were allowed to rest the 3 other days.

\section{Injection of NOX-D21 and mNOX-E36 Inhibitors}

PEGylated mixed L-RNA/DNA Spiegelmer NOX-D21 with the sequence $40 \mathrm{kDaPEG}$-aminohexyl-GCGAUG(dU)GGU GGUGAAGGGUUGUUGGG(dU)GUCGACGCA(dC)GC and the all-RNA Spiegelmer mNOX-E36 with the sequence 40 kDaPEG-aminohexyl-GGCGACAUUGGUUGGGCAU GAGGCGAGGCCCUUUGAUGAAUCCGCGGCCA were manufactured by NOXXON Pharma (Berlin, Germany). Four-week-old mice were injected s.c. three times per week for 4 weeks at a dose of $20 \mathrm{mg} / \mathrm{kg}$. In the group which exercised, injections were performed immediately after exercise.

\section{Physiological Tests}

For serum creatine kinase measurement, blood was taken from the tail artery and centrifuged at $3000 \times g$ for 10 minutes. The biochemical marker creatine kinase was assayed with the Fuji Drychem system (Fuji Film Medical Co Ltd, Tokyo, Japan), as previously described. ${ }^{16}$ Grip strength of both forelimb and hind limb was assessed by a grip strength meter (MK-380M; Muromachi Kikai, Tokyo, Japan), as previously described. ${ }^{21}$ At 8 weeks of age, 2 days after the last training session or the last treatment, mice were sacrificed by cervical dislocation. Gastrocnemius muscles were dissected, and minced for fluorescenceactivated cell sorting (FACS) analysis or flash frozen for histological and immunohistochemical examination or stored at $-80^{\circ} \mathrm{C}$ for cytokine array, enzyme-linked immunosorbent assay (ELISA), and Western blot analysis.

\section{Histopathology and Immunohistochemistry}

Transverse cryosections (20 $\mu \mathrm{m}$ thick) of gastrocnemius muscle from 8-week-old mice after 4 weeks of exercise and/or therapy were stained with hematoxylin and eosin, as previously described. ${ }^{21}$ For immunohistochemistry, cryosections $(8$ $\mu \mathrm{m}$ thick) were fixed in acetone for 15 minutes at $-20^{\circ} \mathrm{C}$. 
Sections were blocked and washed with $1 \%$ bovine serum albumin and $0.5 \%$ Triton X-100 in phosphate-buffered saline (PBS). The following antibodies were used at 1:50 to 1:100 dilutions: rabbit anti-mouse CD68 (ab125212; Abcam, Cambridge, UK) and rat anti-mouse CD206 (MR5D3; Bio-Rad Laboratories, Inc., Hercules, CA). All antibodies were diluted in PBS containing 1\% bovine serum albumin and $0.5 \%$ Triton X-100 and incubated with the tissue sections for either 1 hour at room temperature or overnight at $4^{\circ} \mathrm{C}$. The tissue sections were washed with PBS and incubated with corresponding secondary Alexa 488- or Alexa 594-conjugated antibodies (Life Technologies, Carlsbad, CA), at 1:1000 dilution for 1 hour at room temperature. Glass slides were washed with PBS and mounted in Vectashield (Vector Laboratories, Burlingame, CA) with DAPI. Immunofluorescence was visualized using a BZ-9000 fluorescence microscope (KEYENCE, Osaka, Japan).

Histochemical staining for NADH-tetrazolium reductase was performed by incubation of tissue sections for 30 minutes at $37^{\circ} \mathrm{C}$ in $\mathrm{NADH}$-tetrazolium reductase reaction solution $(0.2 \mathrm{~mol} / \mathrm{L}$ Tris, $1.5 \mathrm{mmol} / \mathrm{L} \mathrm{NADH}$, and $1.5 \mathrm{mmol} / \mathrm{L}$ nitrotetrazolium blue), followed by dehydration through serial dilutions of acetone. Sections were mounted onto slides in Aquamount (Lerner Laboratories, Pittsburgh, PA).

\section{Flow Cytometrical Analyses}

Minced muscles were incubated for 3 hours at $37^{\circ} \mathrm{C}$ with $5 \mathrm{~mL}$ of RPMI 1640 (HyClone, Logan, UT) containing $1 \mathrm{mg} /$ $\mathrm{mL}$ collagenase D and $30 \mu \mathrm{g} / \mathrm{mL}$ DNase I (Roche Diagnostics, Laval, QC, Canada). Samples were filtered through a cell strainer with $70 \mu \mathrm{m}$ mesh size and centrifuged at $800 \times g$ for 5 minutes at room temperature. Pellets were washed three times in staining buffer (PBS containing 2\% fetal bovine serum) and fixed in PBS containing 2\% paraformaldehyde for 20 minutes on ice. Then, cells were permeabilized in staining buffer containing $0.2 \%$ saponin for 30 minutes on ice and incubated with anti-phycoerythrin-coupled anti-CD68 (FA11), anti-Ly6c (RB6-8C5), or anti-F4/80 (CI:A3-1) and allophycocyanin-coupled anti-CD11b (M170) (BD Biosciences, Mississauga, ON, Canada). Data were acquired with a FACSCanto II (BD Biosciences). Isotype controls or omission of primary antibodies, when appropriate, was used to set gates.

\section{Proteome Profiler Cytokine Array}

Muscle tissue samples were disrupted in a homogenizer (Psychotron NS-310EII; Microtec Co, Ltd, Chiba, Japan), and the protein concentrations were determined by the Bio-Rad protein assay (Bio-Rad Life Science, Hercules, CA). The relative expression of cytokines and chemokines in muscle lysates was quantified using the Proteome Profiler Array (Mouse Cytokine Array, Panel A; R\&D Systems Inc., Minneapolis, $\mathrm{MN}$ ). The array was performed according to the manufacturer's specifications with $100 \mu \mathrm{g}$ of total protein. To achieve maximum assay intensity, the blots were incubated overnight. The chemoluminescence signal was generated by incubation with the Super Signal West Femto Chemiluminescent Kit (Thermo Scientific Pierce, Rockford, IL) for 5 minutes. Images were captured using Image Quant LAS 4000 coupled with Image Quant TL software version 1.51h (GE Healthcare, Tokyo, Japan).

\section{ELISA}

Amounts of CCL2 and tissue inhibitor of metalloproteinases (TIMP)-1 in muscle lysates were determined by the Mouse CCL2 (MCP-1) ELISA Ready-SET-Go! (88-7391; eBioscience, San Diego, CA) and the TIMP1 Mouse ELISA kit (ab100745; Abcam), according to the manufacturers' recommendations.

\section{Western Blot}

Proteins from gastrocnemius muscle were separated by SDS-PAGE (12\% polyacrylamide) and electroblotted onto a nitrocellulose membrane. After blocking with $1 \%$ bovine serum albumin, membranes were incubated with the respective antibody at 1:500 to 1:100 dilutions as follows: rabbit anti-mouse C5a (250565; Abbiotech, San Diego, CA), rabbit anti-mouse CD68 (ab125212), rabbit anti-iNOS antibody (ab3523), rabbit anti-myeloperoxidase (ab65871), rabbit antitroponin T T1 (ab83907; Abcam), rabbit anti-CD163 (M-96), rabbit anti-IL-1RA (H-110), rabbit anti-acetyl-CoA carboxylase (C83B10), rabbit anti-AMP-activated protein kinase (AMPK) $31 / 2$ (57C12), goat anti-glyceraldehyde-3-phosphate dehydrogenase (V-18), goat anti-troponin T FS (C-18; Santa Cruz Biotechnology, Inc., Dallas, TX), rabbit anti-MYBPC1 (LS-C144479), and rabbit anti-MYBPC2 (LS-C101947; LSBio, Seattle, WA). Membranes were developed with the Super Signal West Femto Chemiluminescent Kit (Thermo Scientific Pierce), and images were captured using Image Quant LAS 4000 coupled with Image Quant TL software version 1.51h (GE Healthcare).

\section{Statistical Analysis}

Values are reported as means \pm SD. Statistically significant differences between groups were determined by analysis of variance test, followed by Tukey's range test. $P<0.05$ was considered as significant for the analysis of variance test, and a result above the minimal significant difference was considered significant for the Tukey test.

\section{Results}

Effect of Low-Intensity Training on Macrophage Infiltration in Muscle of 8-Week-Old Mice

We assessed the effects of swimming exercise on immune cell populations in wild-type and $m d x$ muscle. 
Immunostaining of the gastrocnemius muscle for CD68, a surface marker of monocytes/macrophages, revealed that $m d x$ mice have higher numbers of intramuscular macrophages than wild-type mice; the highest amount was found in the exercised group. Staining for the M2 macrophage marker, CD206, did not show differences for the presence of M2 macrophages between the groups (Figure 1A and Supplemental Figure S1A). CD68 increased in nonexercised $m d x$ muscles, compared with wild-type ones, as shown by Western blot (Figure 1B). Low-intensity training of $m d x$ mice further increased the CD68 level, which is consistent with the findings revealed by immunohistochemistry (Figure 1A).

Western blot analysis also showed that the M1 macrophage marker iNOS was increased in muscle of nonexercised $m d x$ mice, but not in exercised wild-type or exercised $m d x$ mice (Figure 1B). The level of M2 macrophages was assessed with the marker CD163, because antibodies against CD206 were not effective on Western blots. This level was significantly higher in muscle of $m d x$ mice, but the differences between nonexercised and exercised mice were not significant (Figure 1B). This result is concordant with the absence of a visible difference between $m d x$ groups in immunostainings against CD206 (Figure 1A).

To set apart mature macrophages from the monocyte/ macrophage population, we performed a FACS analysis on the basis of separation of myeloid cells $\left(\mathrm{CD} 11 \mathrm{~b}^{+}\right)$, followed by a selection of monocytes $\left(\mathrm{Ly}_{6} \mathrm{C}^{+}\right)$, macrophages $\left(\mathrm{F} 4 / 80^{+}\right)$, and monocyte/macrophage $\left(\mathrm{CD} 8^{+}\right)$populations In accord with the results of immunostaining and Western blot, we found an increased quantity of $\mathrm{CD}^{+} 8^{+} / \mathrm{CD} 11 \mathrm{~b}^{+}$ cells in exercised $m d x$ muscles, compared with nonexercised ones (Figure 1C). We identified two subpopulations of Ly6C cells (namely, CD11b ${ }^{-} / \mathrm{Ly} 6 \mathrm{C}^{+}$and $\mathrm{CD} 11 \mathrm{~b}^{+} / \mathrm{Ly} 6 \mathrm{C}^{+}$) whose abundance remained unaltered by exercise. The $\mathrm{CD} 11 \mathrm{~b}^{+} / \mathrm{Ly} 6 \mathrm{C}^{+}$population included both monocytes and neutrophils, but we were not able to separate them. In contrast with $\mathrm{Ly}^{+} \mathrm{c}^{+}$populations, the level of $\mathrm{F} 4 / 80^{+} /$ $\mathrm{CD}_{11 \mathrm{~b}^{+}}$cells was significantly increased in muscle of exercised $m d x$ mice, compared with nonexercised ones. This result suggests that $\mathrm{CD} 68^{+}$cells were mature macrophages rather than infiltrated monocytes.

\section{Effect of Low-Intensity Training on Cytokine and Chemokine Levels in Muscle of 8-Week-Old Mice}

Cytokine and chemokine levels in gastrocnemius muscle extracts from wild-type and $m d x$ mice were determined by multiplex cytokine/chemokine array analysis (Figure 2, A-C). One hour after the last exercise, complement C5a, TIMP-1, and the chemokine CCL2 were found to be increased in muscle of nonexercised $m d x$ mice, as confirmed by Western blot for C5a (Figure 2D) and ELISA for CCL2 (Figure 2E) and TIMP-1 (Figure 2F). Taken together, LIT significantly decreased the levels of CCL2 and TIMP-1 in $m d x$ muscle. However, the level of C5a was not affected by LIT.
Inhibition of Complement C5a in Muscle of 4- to

\section{8-Week-Old Mice}

Using the chemokine/cytokine panel and ELISA, we found that complement C5a and CCL2 increased in $m d x$ muscle and that LIT decreased the level of CCL2 (Figure 2). Both molecules are chemoattracting agents playing a crucial role in coordination of the inflammatory response. ${ }^{22,23} \mathrm{We}$ therefore hypothesized that inhibition of C5a or CCL2 would mimic LIT and hence rescue the $m d x$ phenotype. Four-week-old $m d x$ mice were subjected to 4 weeks of LIT while being treated with the L-aptamer inhibitors NOX-D21 or mNOX-E36 to inhibit signaling of C5a and CCL2, respectively (Figure 3A). Treatment with NOX-D21 significantly increased the grip strength and the force/weight ratio of nonexercised $m d x$ mice, compared to untreated $m d x$ mice (Figure 3B). Improvement of force in the treated, nonexercised $m d x$ group was equivalent to 4 weeks of LIT in $m d x$ mice. Interestingly, exercise and treatment together failed improving the phenotype of $m d x$ mice. Creatine kinase levels of treated and exercised mice were not significantly different (Figure 3C). No significant effect of CCL2 inhibition by mNOX-E36 on grip strength of $m d x$ mice was observed. Thus, we focused on the effects of C5a inhibition by NOX-D21.

\section{State of 8-Week-Old $m d x$ Mice after NOX-D21 Treatment or Low-Intensity Training}

The grip strength of $m d x$ mice increased after treatment with NOX-D21 or LIT (Figure 3B). This improvement could be because of reduced damage in muscle or a change in fiber composition. We evaluated damage by hematoxylin and eosin and IgG staining and changes of fiber composition by NADH staining (Figure 4, A and B) and Western blot analysis of proteins involved in energy metabolism (Figure 5A) or contraction (Figure 5B).

We found that the percentage of centronucleated fibers in gastrocnemius muscle was not significantly different between the $m d x$ groups. However, the amount of necrotic fibers (IgG positive) was significantly lower in treated nonexercised $m d x$ muscles, compared with control. Numbers of necrotic fibers tended to be lower in muscles of exercised, but non-treated $m d x$ mice, compared with controls, but the difference was not significant. Amounts of necrotic fibers were also significantly higher in muscles of treated-exercised $m d x$ mice, compared with exercised $m d x$ or treated $m d x$ ones. These results suggest that C5a complement inhibition prevents fiber damage, whereas LIT does not. Furthermore, exercise during the treatment compromises the protective effect of C5a complement inhibition.

Numbers of fibers with a strong oxidative metabolism (NADH-positive fibers) tended to be lower in treated muscles and higher in treated and exercised ones, compared with control or exercised $m d x$ mice, but the difference was not significant (Figure 4B). Likewise, Western blot analysis showed that the expression of proteins involved in energy 
A
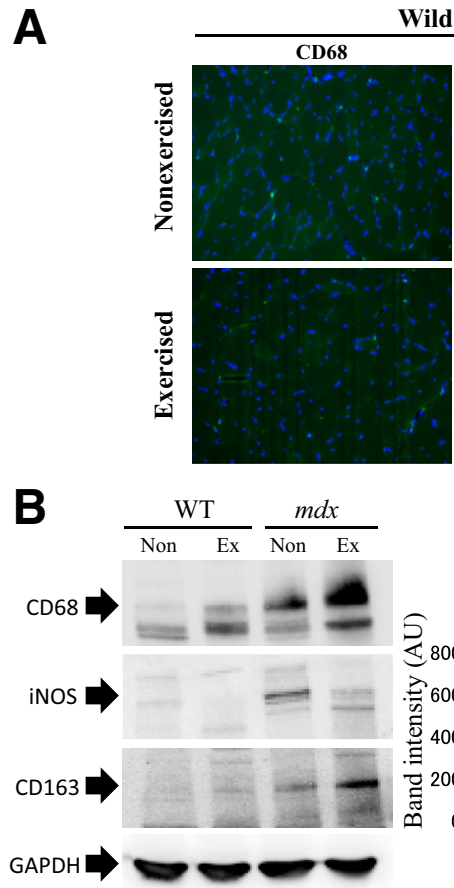

B

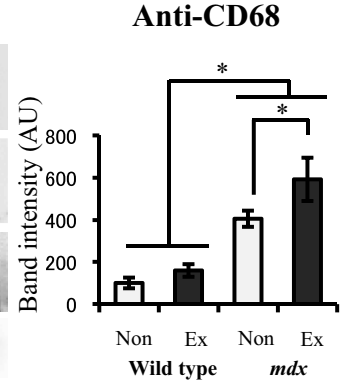

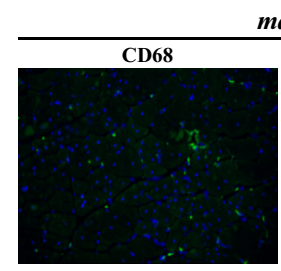

$m d x$
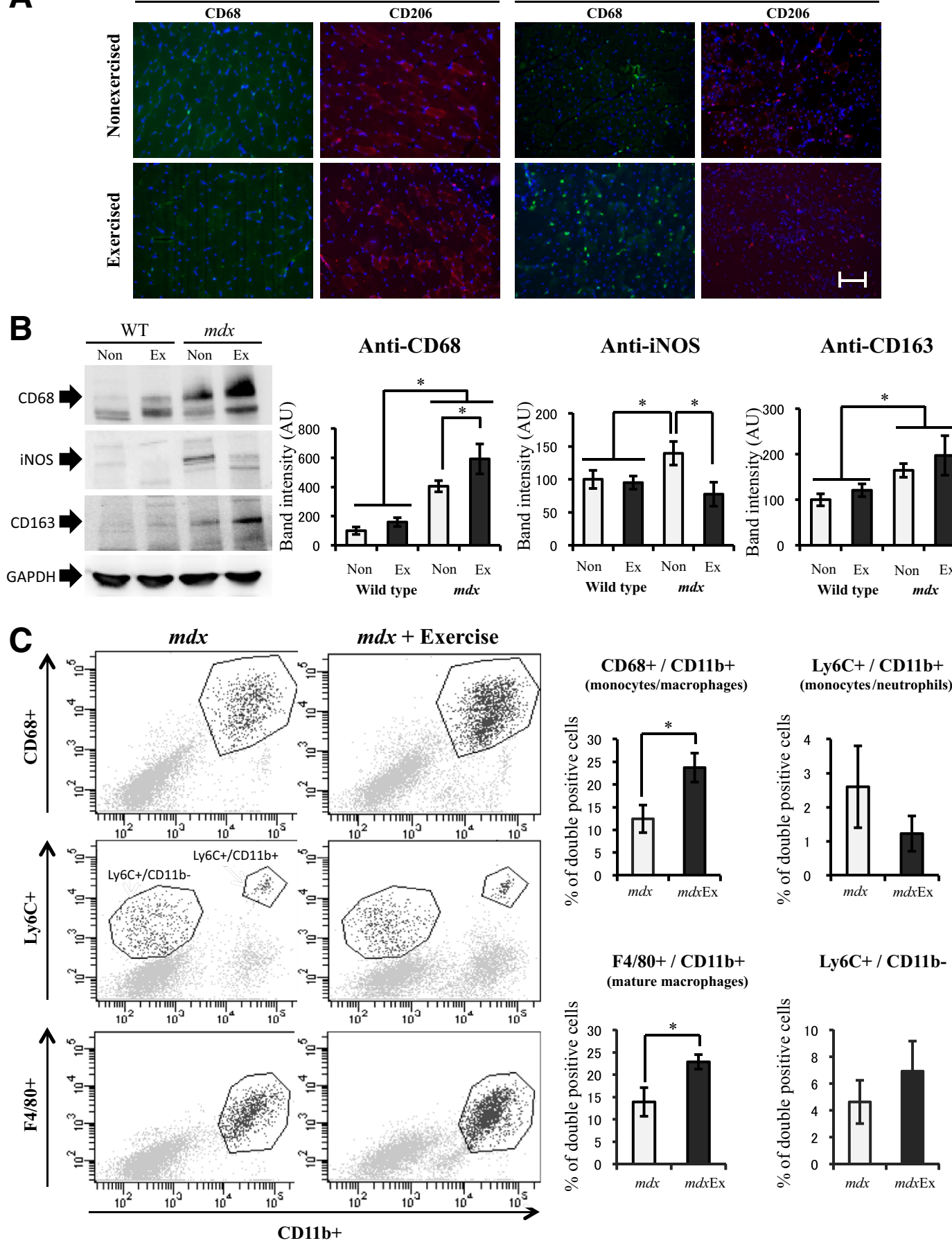

F4/80+ / CD11b+

(mature macrophages)

Ly6C+ / CD11b-
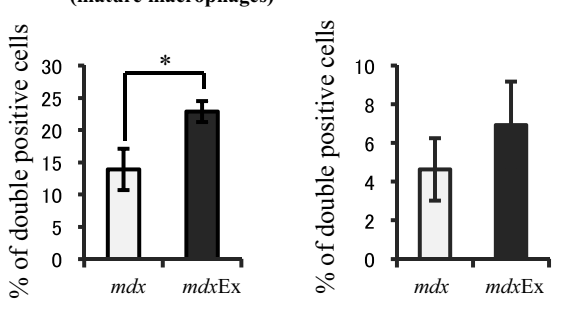

Figure 1 Markers of immune cells in gastrocnemius muscle of 8-week-old wild-type (WT) and mdx mice after 4 weeks of low-intensity training. A: Monocyte and macrophage populations were identified by immunofluorescence staining of gastrocnemius muscle from WT and $m d x$ mice, with anti-CD68 (green), antiCD206 (red) antibodies and corresponding DAPI (blue) staining. B: Expression of CD68, inducible nitric oxide synthase (iN0S), and CD163 was assessed by Western blot and normalized to glyceraldehyde-3-phosphate dehydrogenase (GAPDH). C: Composition of monocyte and macrophage populations was confirmed by flow cytometry with the following fluorescently labeled antibodies: phycoerythrin (PE)-CD68, PE-Ly6C, PE-F4/80, and allophycocyanin-CD11b. Data are expressed as means \pm SD (B and $\mathbf{C}) . n=4$ to 5 mice per group. ${ }^{*} P<0.05$ indicates a significant difference between two groups. Scale bar $=$ $100 \mu \mathrm{m}$ (A). AU, arbitrary unit; Ex, exercised; Non, nonexercised.

metabolism, such as acetyl-CoA carboxylase and AMPK $\beta$, was significantly lower in treated muscles, compared with treated and exercised ones (Figure 5A). Furthermore, levels of the fast isoform of troponin $\mathrm{T}$ and of myosin binding protein $\mathrm{C}$ were significantly higher and the level of the slow isoform of myosin binding protein $\mathrm{C}$ was significantly lower in treated muscles, compared with treated and exercised ones (Figure 5B). These results support the hypothesis of a 
A Mouse Cytokine Array Panel A Coordinates

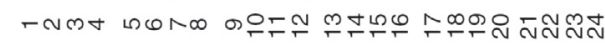
A $\bigcirc$

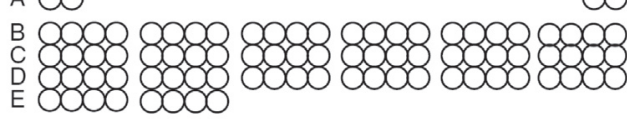
F $\infty$

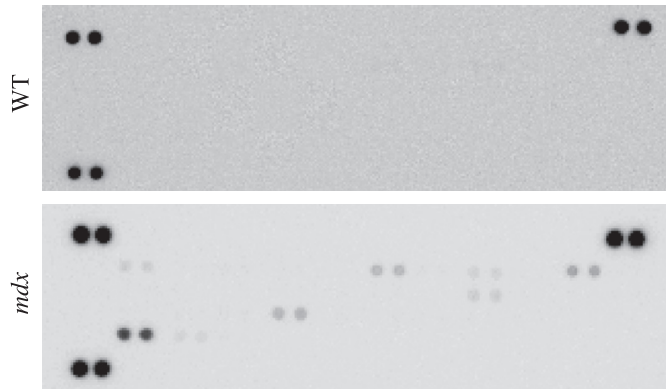

$\infty$

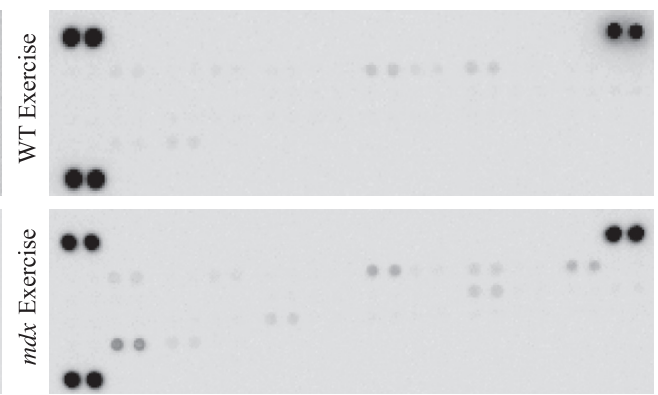

B

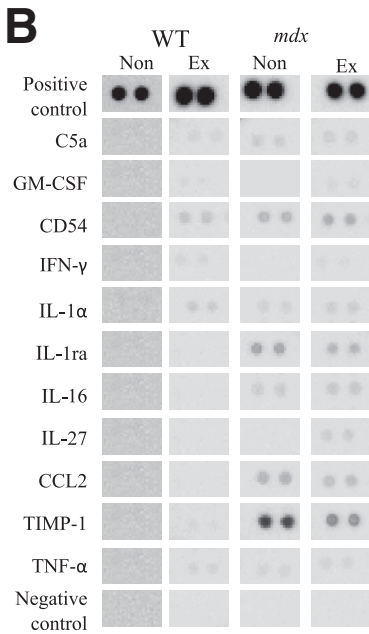

D C5a expression

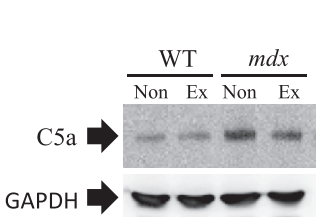

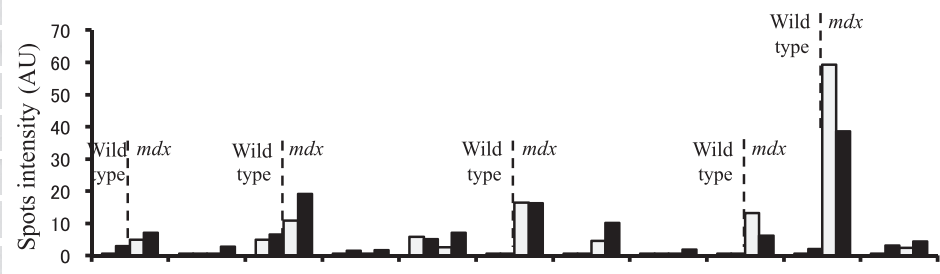

C5a GM-CSF CD54 IFN- $\gamma \quad$ IL-1 $\alpha \quad$ IL-1ra $\quad$ IL-16 $\quad$ IL-27 $\quad$ CCL2 $\quad$ TIMP-1 TNF- $\alpha$

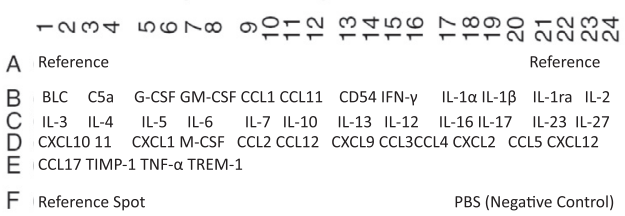

A Reference

Reference

B BLC C5a G-CSF GM-CSF CCL1 CCL11 CD54 IFN- $\quad$ IL-1 $\alpha$ IL-1及 IL-1ra IL-2

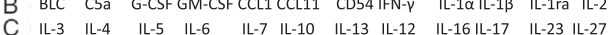

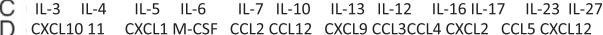

E CCL17 TIMP-1 TNF- $\alpha$ TREM-1

F Reference Spot PBS (Negative Control)

C

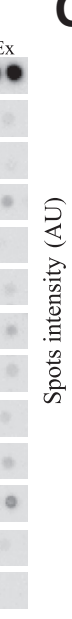

\section{E CCL2 expression}

F TIMP-1 expression
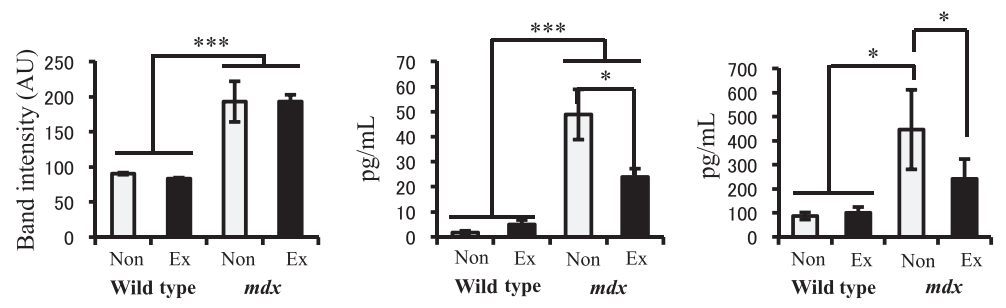

Figure 2 Expression of cytokines and chemokines in gastrocnemius muscle of 8-week-old wild-type (WT) and $m d x$ mice after 4 weeks of low-intensity training. Relative expression of cytokines and chemokines in muscle lysates was quantified using the Proteome Profiler array. A: Total array images. B: Cropped array images. C: Quantification of representative data. Open bars, nonexercised; closed bars, exercised mice. Expression profile of C5a complement, and chemokine ligand 2 (CCL2) and tissue inhibitor of metalloproteinases-1 (TIMP-1) expression was confirmed by Western blot (D) and enzyme-linked immunosorbent assay (E and $\mathbf{F}$ ), respectively. Ponceau red staining is shown as loading control. ${ }^{*} P<0.05, * * * P<0.001$ indicate a significant difference between two groups. Data are expressed as means \pm SD (D-F). AU, arbitrary unit; Ex, exercised; GAPDH, glyceraldehyde-3-phosphate dehydrogenase; GM-CSF, granulocyte-macrophage colonystimulating factor; IFN- $\gamma$, interferon- $\gamma$; Non, nonexercised; TIMP-1, tissue inhibitor of metalloproteinases- 1 ; TNF- $\alpha$, tumor necrosis factor- $\alpha$.

switch toward glycolytic fast-type fibers in treated muscles. On the opposite, treated and exercised ones tended toward oxidative slow-type fibers. Fast muscles are more likely to be solicited in the grip strength test, which could be a second reason why treatment with NOX-D21 improved grip strength, whereas treatment and exercise together caused a reduction of grip strength.

\section{Effect of NOX-D21 Treatment or Low-Intensity Training on Macrophage Infiltration}

Immunostaining of gastrocnemius muscle for the monocyte/macrophage marker CD68 suggested that nonexercised $m d x$ mice had slightly more infiltration of these cells than wild-type mice. Both exercise and NOX-D21 
A

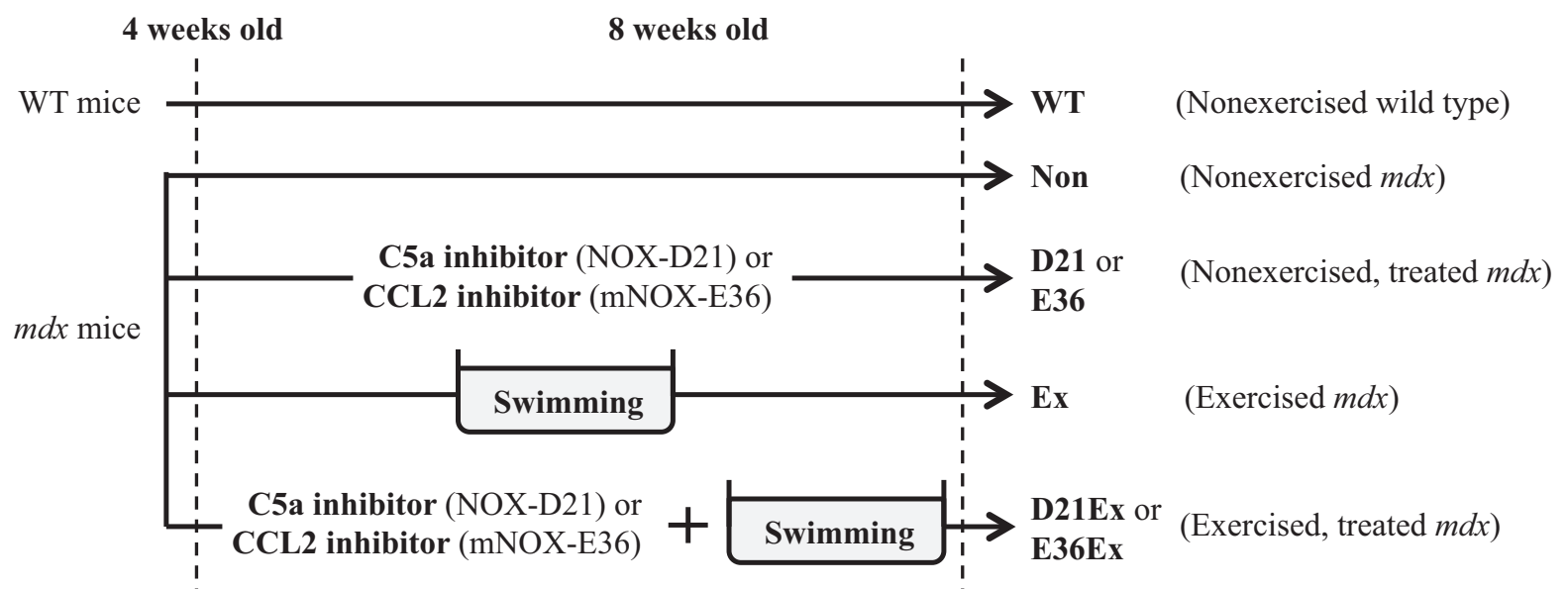

B

C5a inhibition (NOX-D21)

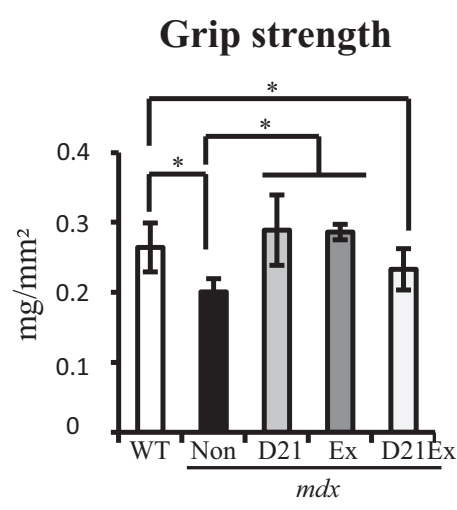

Grip strength

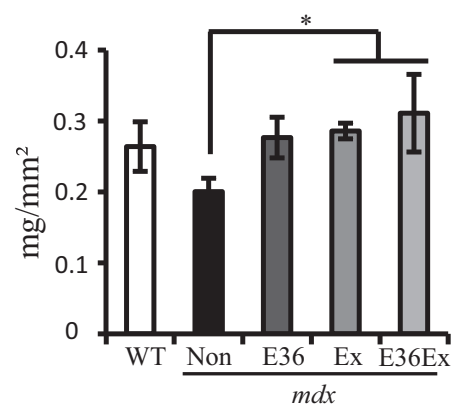

C

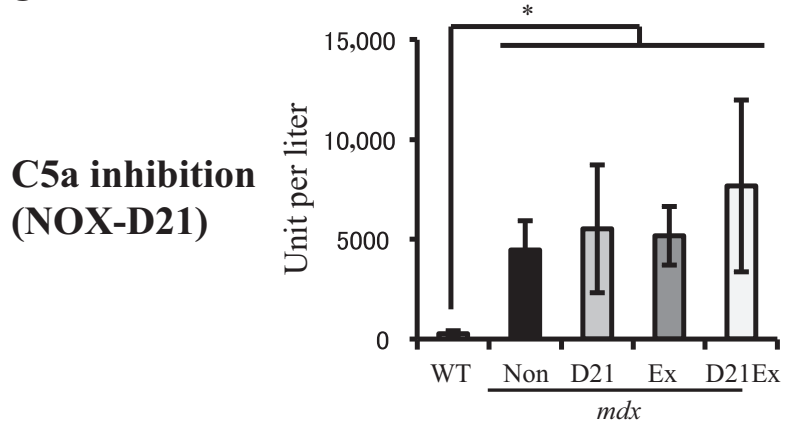

Weight

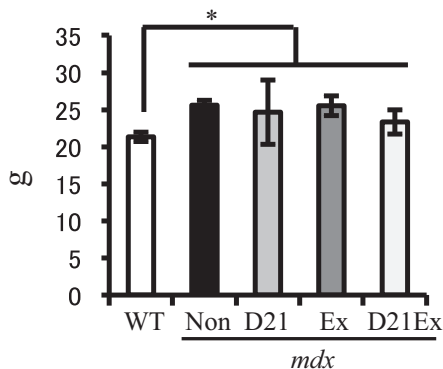

Weight

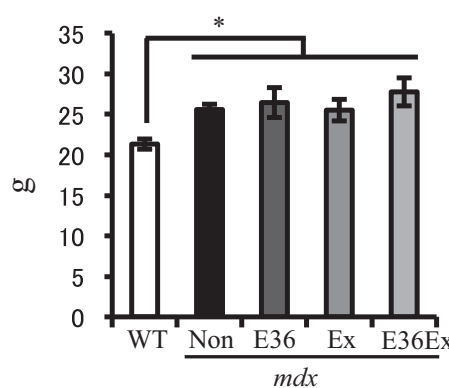

Serum creatine kinase

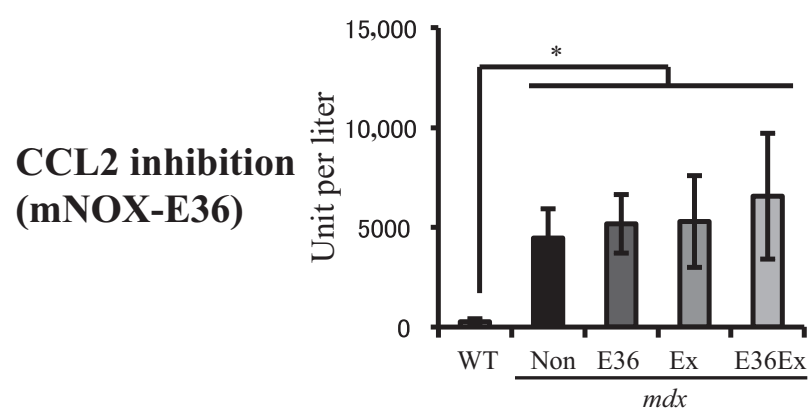

Figure 3 Force and weight of mice treated with the C5a inhibitor NOX-D21, the chemokine ligand 2 (CCL2) inhibitor mNOX-E36, or subjected to low-intensity training. A: Mice were treated with L-aptamers (C5a inhibitor NOX-D21 or CCL2 inhibitor mNOX-E36) or exercised according to the experimental plan II. B: Functional readout parameters. C: Level of serum creatine kinase. Data are expressed as means $\pm \mathrm{SD}$ (B and $\mathbf{C})$. ${ }^{\star} P<0.05,{ }^{*} P<0.01$ indicate a significant difference between two groups. WT, wild type. 
A
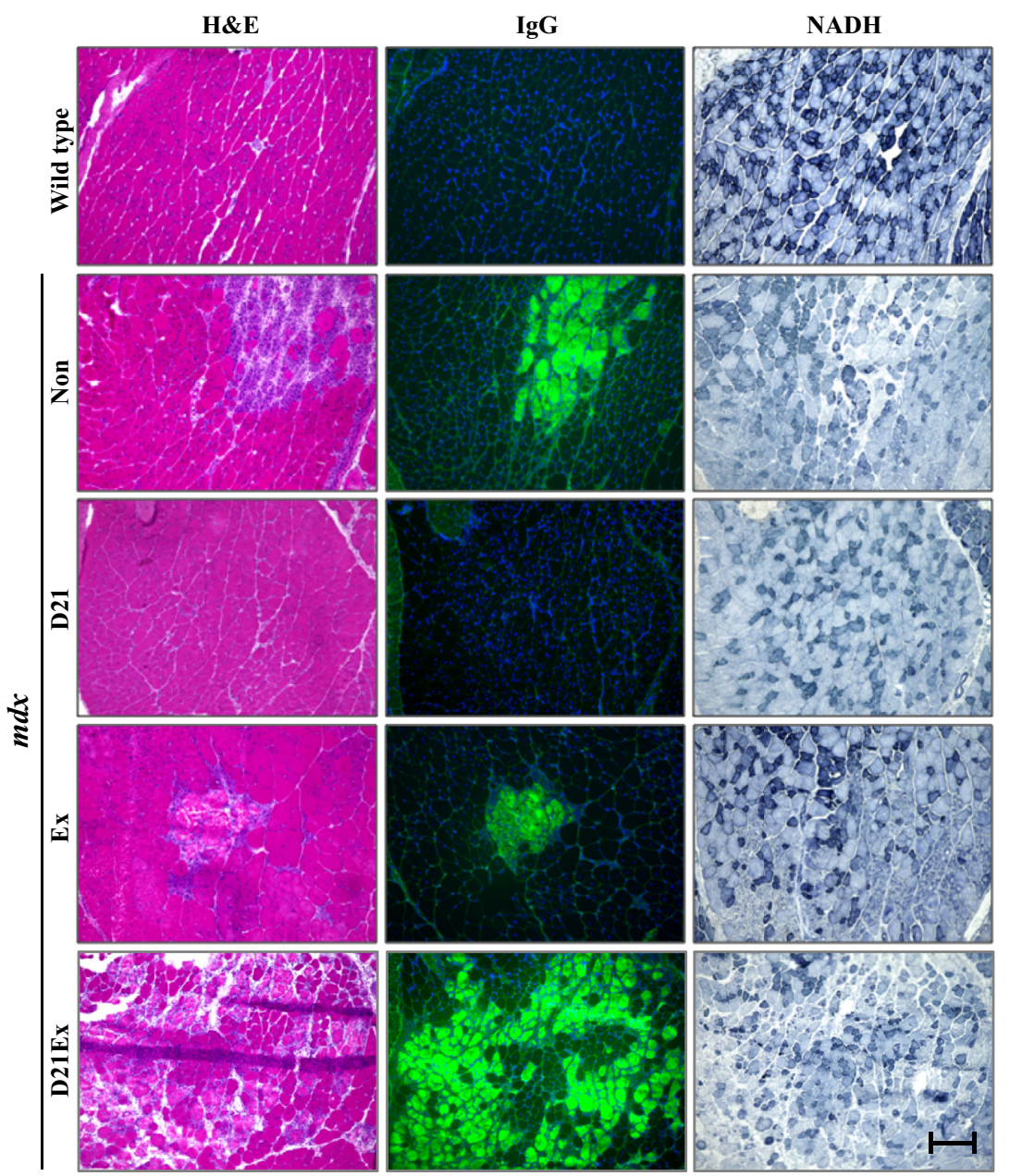

B

Centronucleated fibers

IgG positive fibers

NADH positive fibers
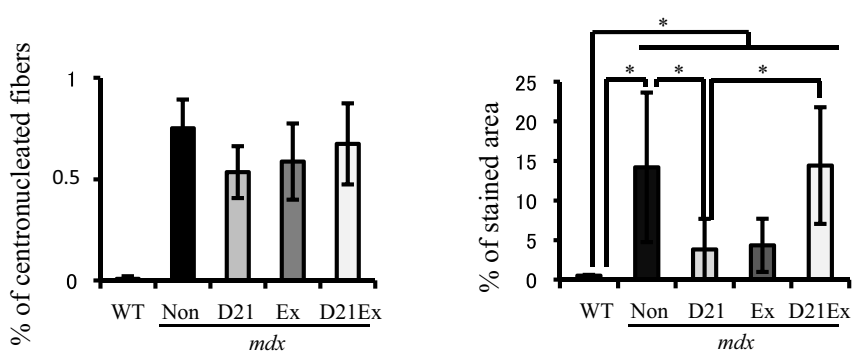

Figure 4 Histological evaluation of muscle from mice treated with the C5a inhibitor NOX-D21 or subjected to low-intensity training. A: Hematoxylin and eosin (H\&E), IgG, and NADH stainings of gastrocnemius muscles from wild-type (WT) and $m d x$ mice. B: Corresponding ratios of centronucleated, IgG-positive, and NADH-positive fibers calculated from A. Data are expressed as means \pm SD (B). ${ }^{*} P<0.05$ indicates a significant difference between two groups. Scale bar $=200 \mu \mathrm{m}(\mathbf{A})$. Ex, exercised; Non, nonexercised.

treatment further increased the number of $\mathrm{CD}^{+} 8^{+}$cells. Staining for the M2 macrophage marker CD206 showed no differences between the groups (Figure 6A and Supplemental Figure S1B). Subsequently, the presence of $\mathrm{CD}^{+} 8^{+}$, $\mathrm{NNOS}^{+}$(M1 macrophages), and $\mathrm{CD} 163^{+}$ (M2 macrophages) in gastrocnemius muscle was quantified by Western blot. As expected, both NOX-D21-treated and exercised $m d x$ groups showed a significantly higher amount of $\mathrm{CD}^{+} 8^{+}$cells compared to both wild-type animals and nonexercised $m d x$ controls. The difference between the NOX-D21-treated and the exercised group was not significant (Figure 6B). Comparison of iNOS and CD163 expression between the NOX-D21-treated and the control $m d x$ mice showed a ratio of M1/M2 macrophages in favor of M1 macrophages in animals treated with NOXD21, as well in treated-exercised mice (Figure 6B). 

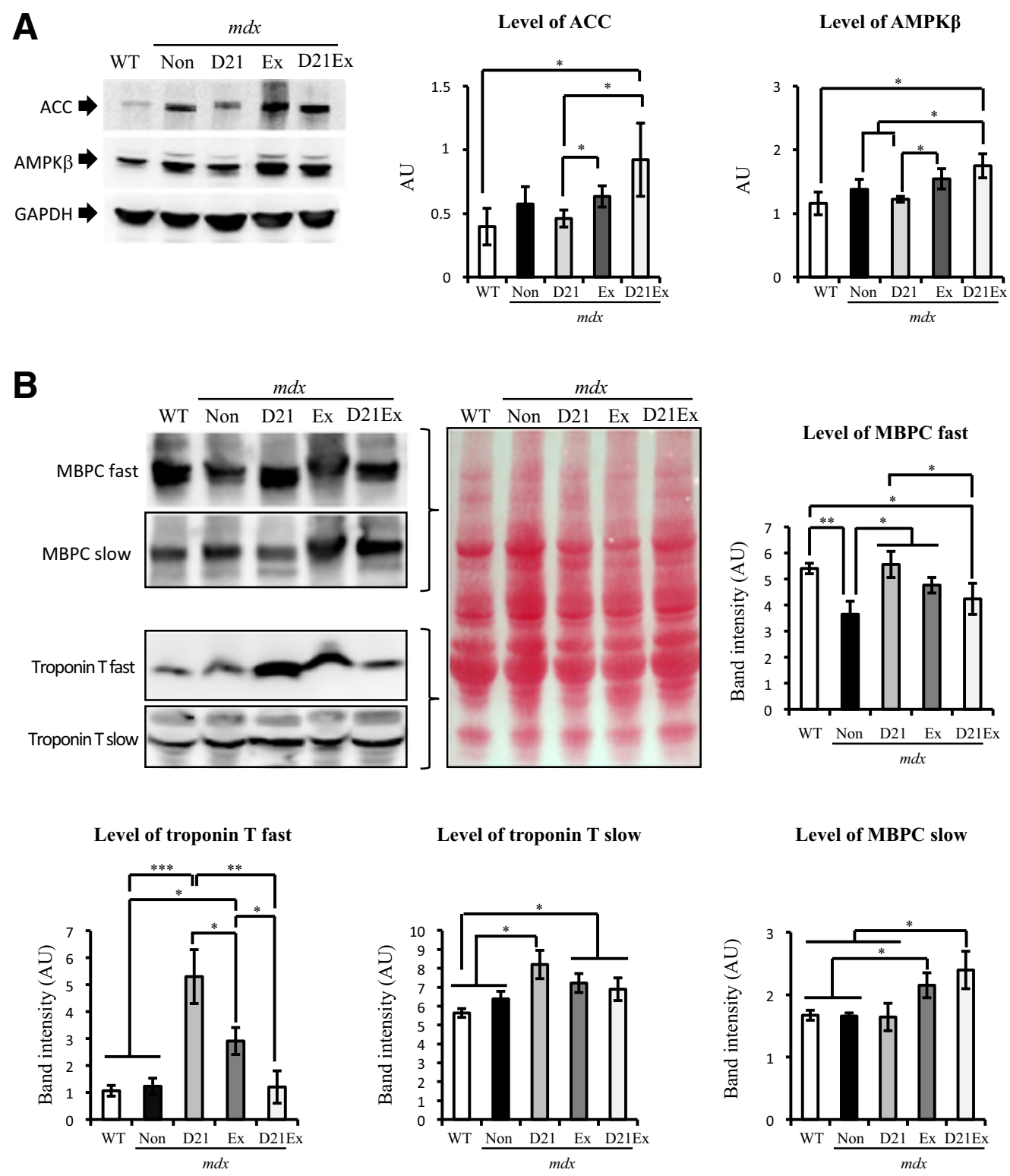

Figure 5 Expression of proteins in gastrocnemius muscle of $m d x$ mice treated with NOX-D21 and/or subjected to low-intensity training. Expression of acetyl-CoA carboxylase (ACC) and AMP-activated protein kinase (AMPK) was evaluated by Western blot and normalized to glyceraldehyde-3-phosphate dehydrogenase (GAPDH). A: Western blot of all three proteins was performed on the same membrane, but the positions of the bands D21 and Ex were interchanged. B: Expression of myosin binding protein $\mathrm{C}$ (MBPC) and troponin T, fast and slow isoforms, was evaluated by Western blot and normalized to Ponceau red staining. Data are expressed as means \pm SD. ${ }^{*} P<0.05$, ${ }^{* *} P<0.01$, and ${ }^{* *} P<0.001$ indicate a significant difference between two groups. $\mathrm{AU}$, arbitrary unit; Ex, exercised; Non, nonexercised; WT, wild type.

FACS analysis of monocyte $\left(\mathrm{Ly}^{+} \mathrm{C}^{+}\right)$, macrophage $\left(\mathrm{F} 4 / 80^{+}\right)$, and monocyte/macrophage $\left(\mathrm{CD} 68^{+}\right)$populations confirmed that $\mathrm{CD}^{+} 8^{+} / \mathrm{CD} 11 \mathrm{~b}^{+}$cells increased in NOXD21-treated or exercised $m d x$ muscles, compared with nonexercised ones (Figure 6C). Inhibition of C5a significantly decreased the quantity of monocytes/neutrophils $\left(\mathrm{CD}_{11 \mathrm{~b}}{ }^{+} / \mathrm{Ly}_{6 \mathrm{C}}{ }^{+}\right)$in muscle of NOX-D21-treated $m d x$ mice, compared with control ones, which was concordant with the fact that C5a acts as a chemoattractant for these two populations. ${ }^{24}$ However, Western blot analysis for the neutrophil enzyme myeloperoxidase showed no difference of expression between groups (Figure 7F). Finally, the quantity of mature macrophages $\left(\mathrm{F} 4 / 80^{+} / \mathrm{CD} 11 \mathrm{~b}^{+}\right)$was significantly increased in muscle of both treated and exercised mice, compared with nonexercised ones. This result suggests that treatment with NOX-D21 or exercise alone leads to an increased presence of differentiated $\mathrm{F} 4 / 80^{+}$macrophages.

Cytokine and Chemokine Levels in Gastrocnemius Muscle of 8-Week-Old $m d x$ Mice after NOX-D21 Treatment or Low-Intensity Training

Cytokine and chemokine levels in gastrocnemius muscle extracts were determined by multiplex cytokine/chemokine 
A

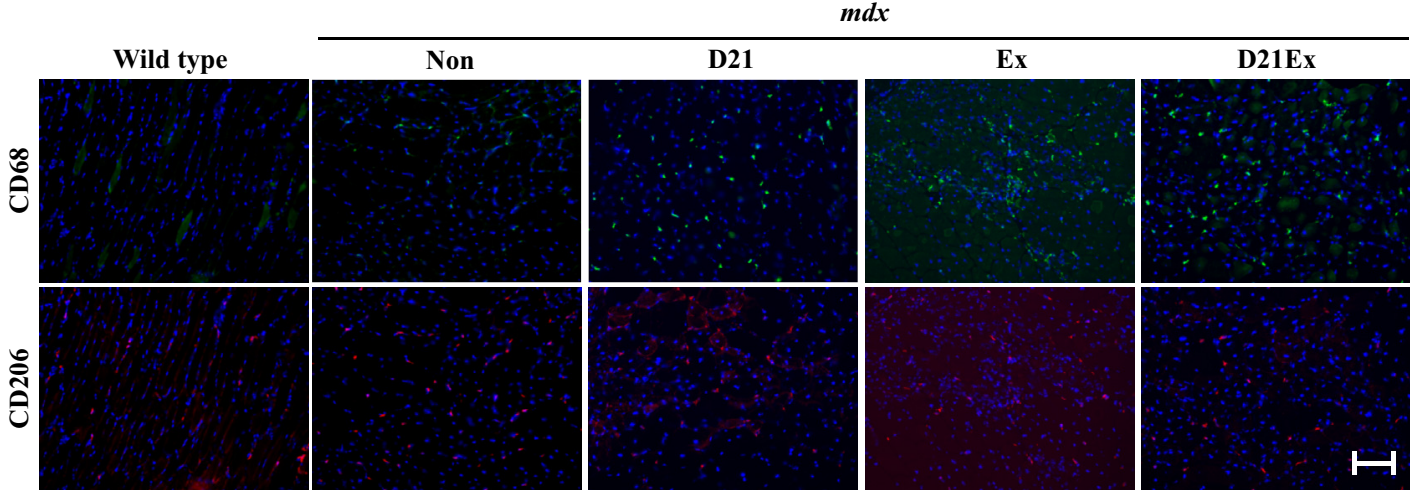

B

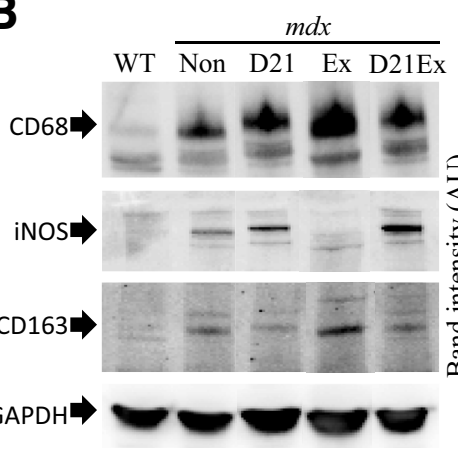

Anti-CD68

Anti-iNOS

Anti-CD163

C
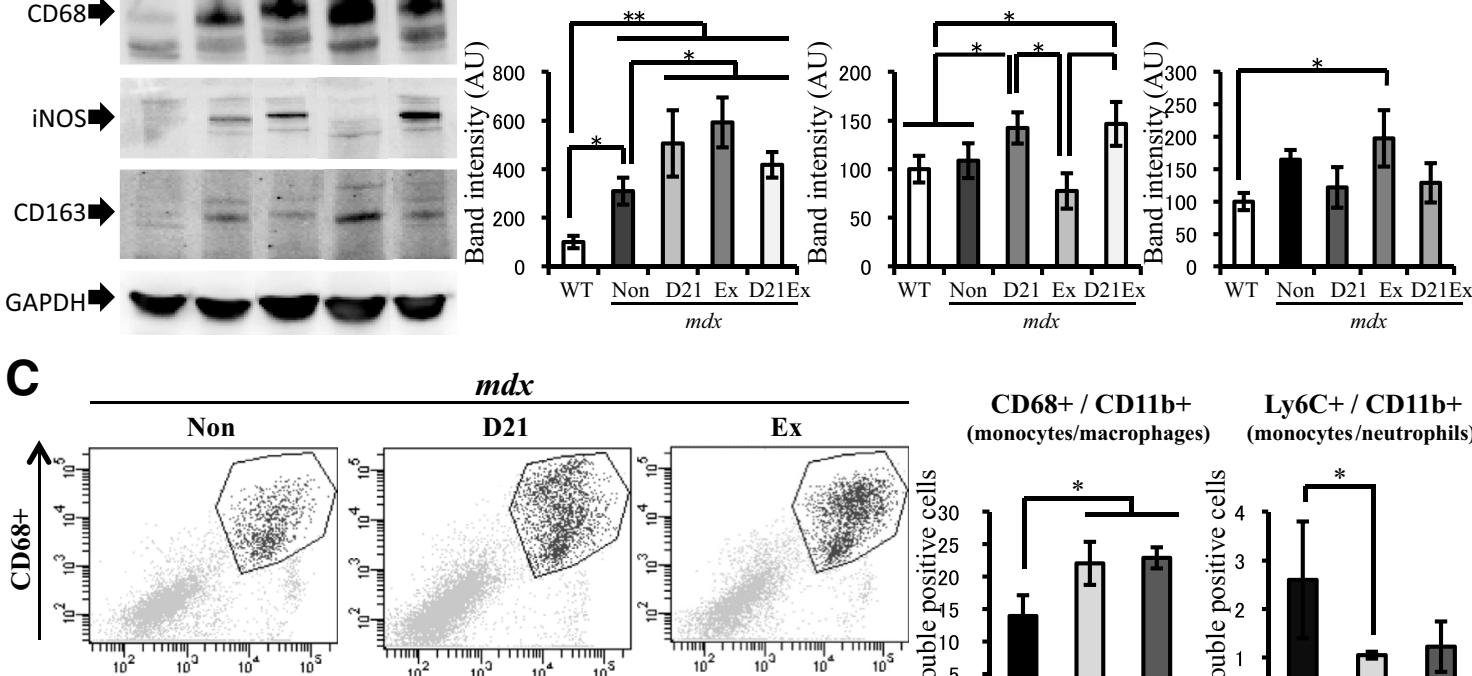

CD68+ / CD11b+

Ly6C+ / CD11b+ (monocytes/macrophages) (monocytes/neutrophils)
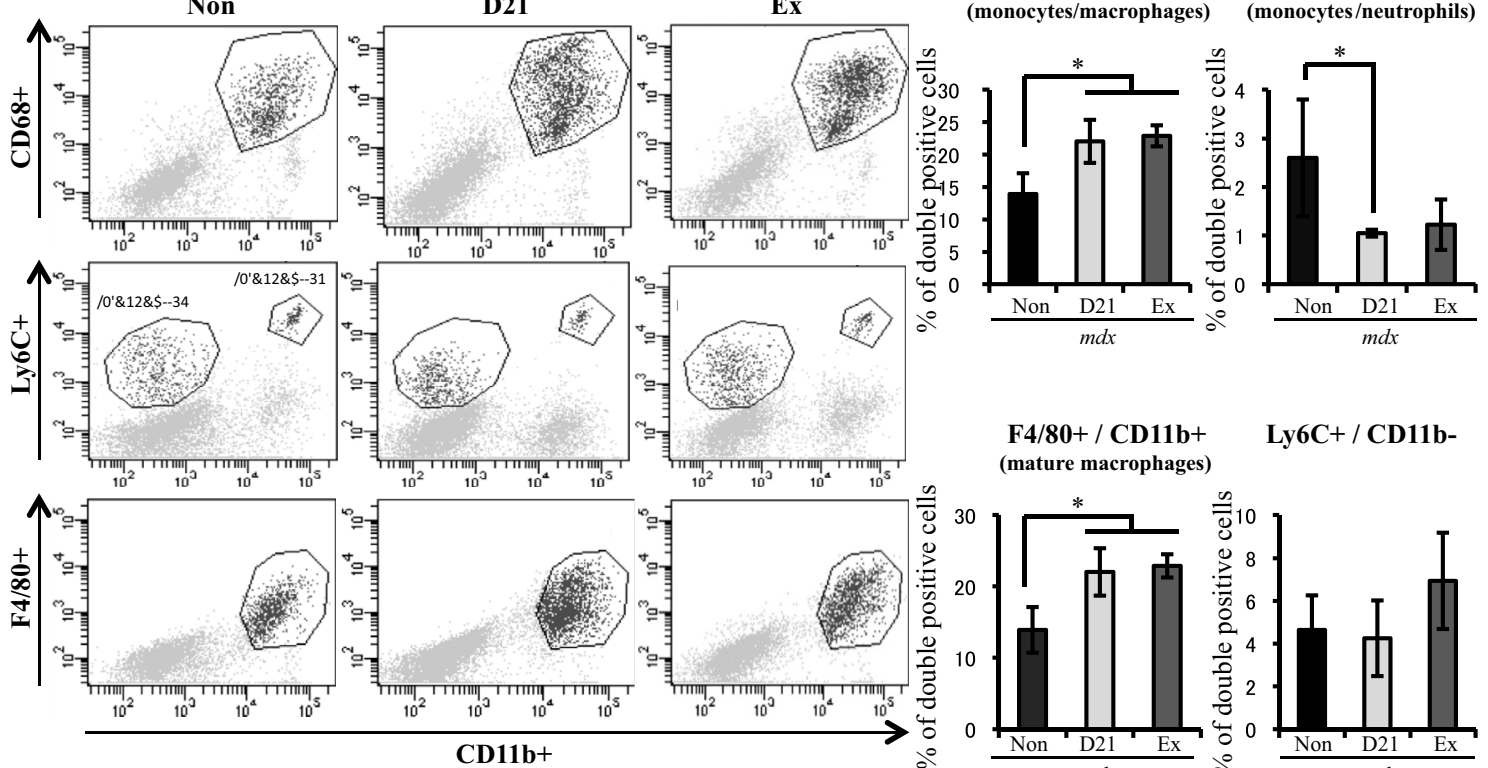

F4/80+ / CD11b+ (mature macrophages)

Ly6C+ / CD11b-
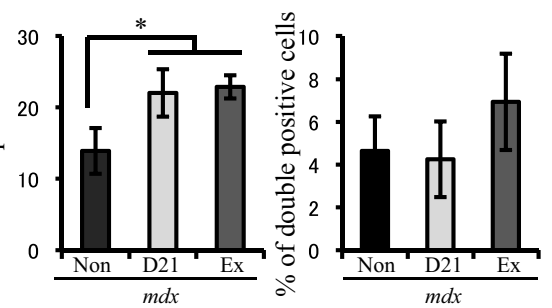

Figure 6 Markers of immune cells in gastrocnemius muscle of $m d x$ mice treated with NOX-D21 and/or subjected to low-intensity training. A: Monocyte and macrophage populations were identified by immunofluorescence staining of gastrocnemius muscle with anti-CD68 (green) or anti-CD206 (red) antibodies and by DAPI staining (blue). B: Expression of CD68, inducible nitric oxide synthase (iNOS), and CD163 was assessed by Western blot and normalized to glyceraldehyde-3-phosphate dehydrogenase (GAPDH). Western blots were performed on the same membrane, but the positions of the bands D21 and Ex were interchanged. C: Composition of monocyte and macrophage populations was confirmed by flow cytometry with the following fluorescently labeled antibodies: phycoerythrin (PE)-CD68, PE-Ly6C, PE-F4/80, and allophycocyanin-CD11b. Data are expressed as means $\pm \mathrm{SD}(\mathbf{B}$ and $\mathbf{C})$. ${ }^{*} P<0.05,{ }^{*} P<0.01$ indicate a significant difference between two groups. Scale bar $=100 \mu \mathrm{m}(\mathbf{A})$. AU, arbitrary unit; Ex, exercised; Non, nonexercised; WT, wild type.

array analysis (Figure 7, A and B), as shown in Figure 1 for untreated mice. As expected, the presence of complement C5a was not affected by treatment with NOX-D21, because the L-aptamer acts by binding its target protein and inhibits its interaction with the receptor. ${ }^{25}$ We found that the level of IL-1RA was significantly higher in $m d x$ gastrocnemius muscle compared to wild-type muscle (Figure $7 \mathrm{C}$ ), as confirmed by Western blot (Figure 7D). Treatment with 
A

A Mouse Cytokine Array Panel A Coordinates - Мलन மழஈ

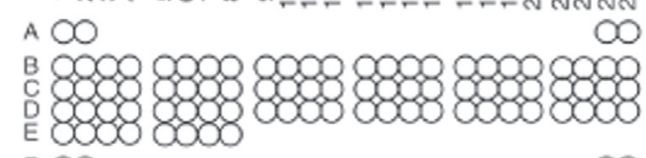

$\mathrm{F} \bigcirc$

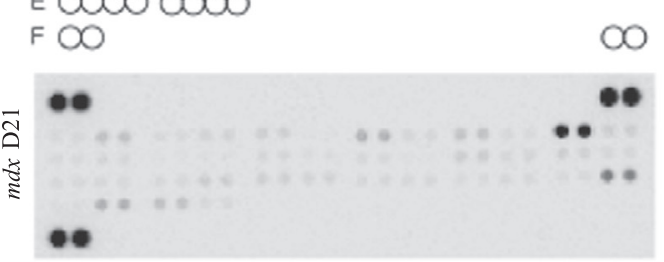

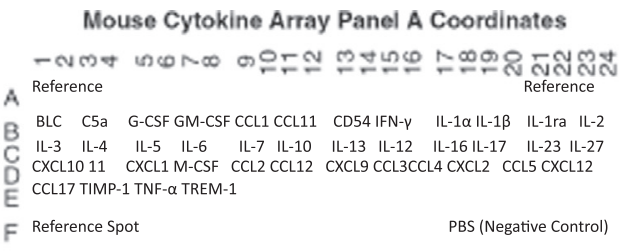

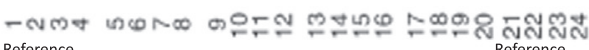

Reference

8 BLC C5a G-CSF GM-CSFCCLCC

F Reference Spot

B
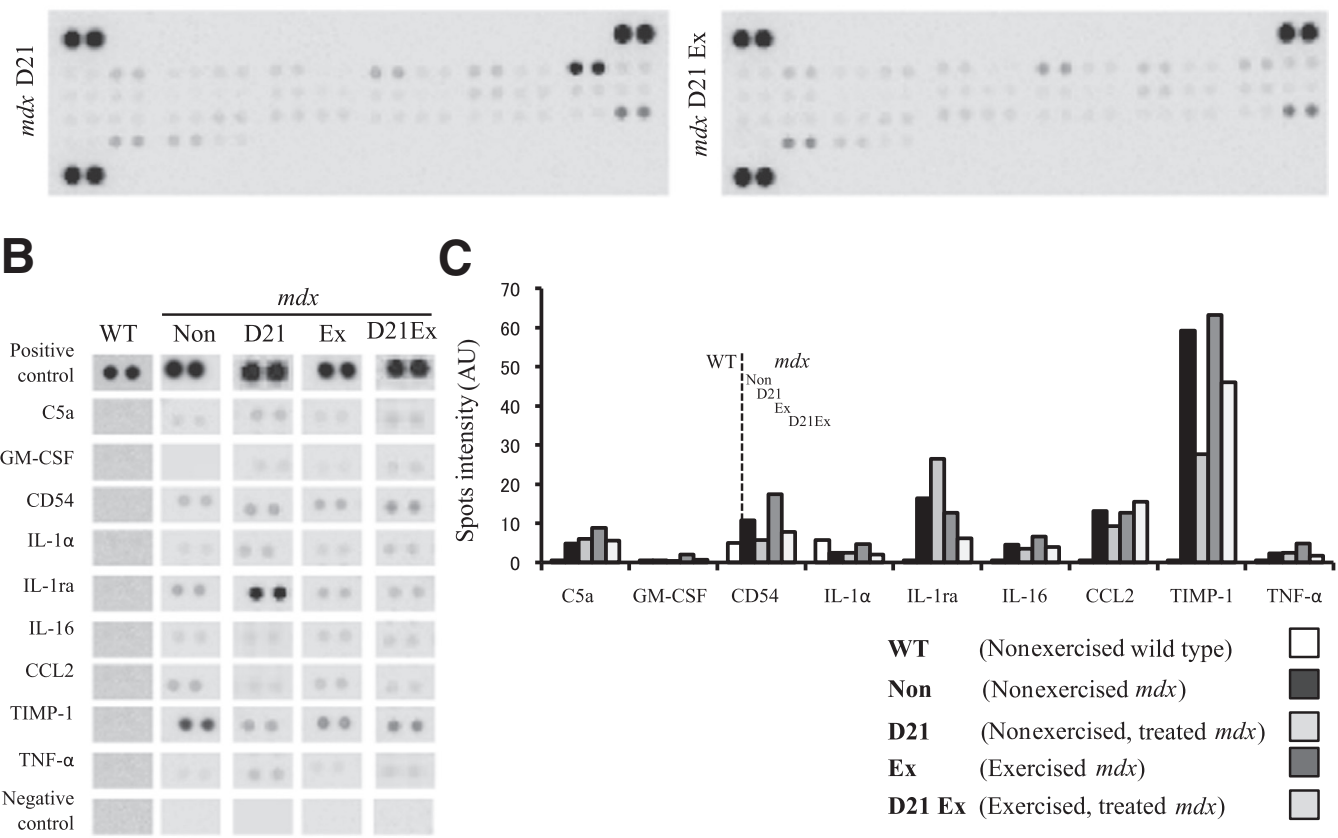

C
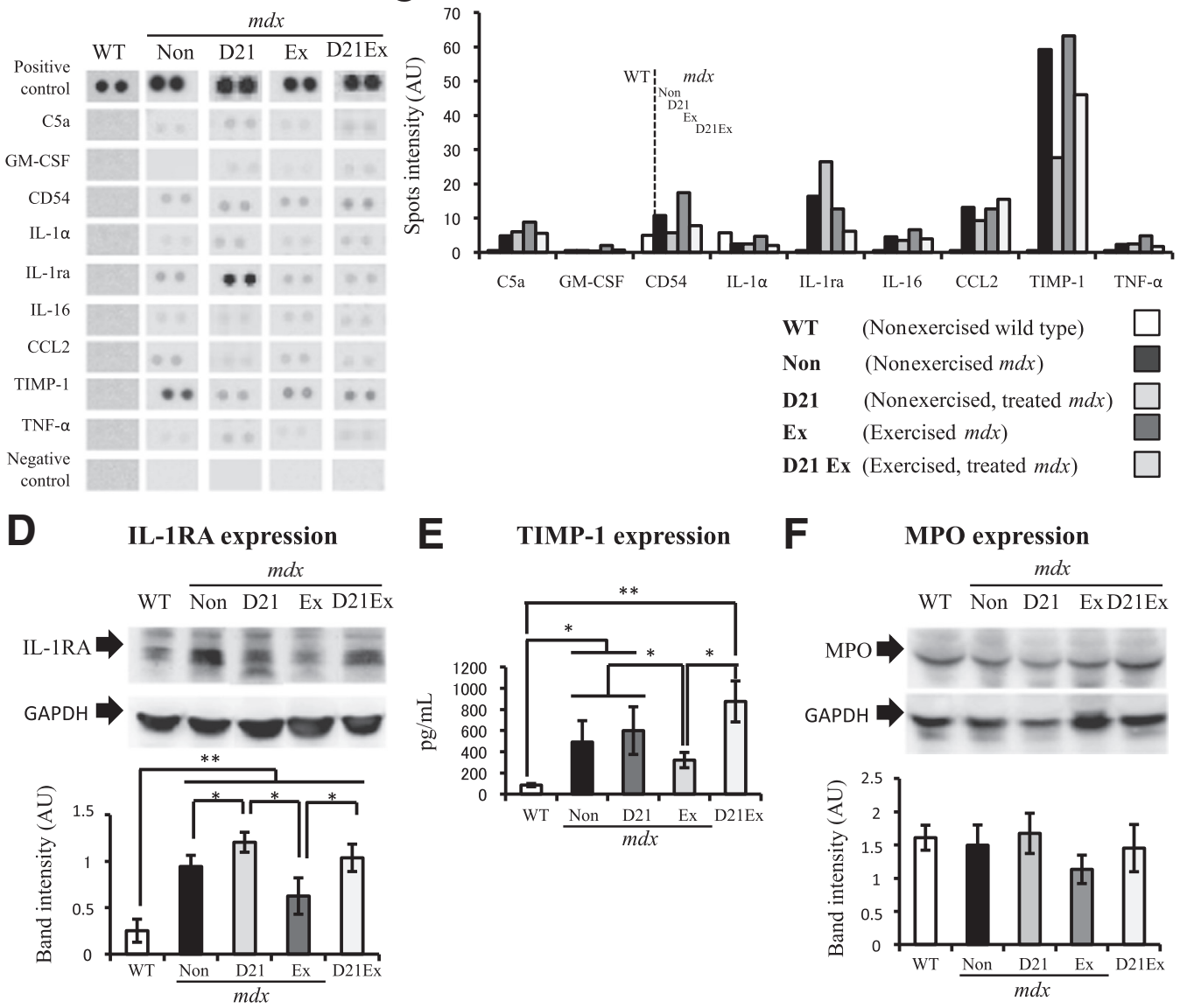

E TIMP-1 expression $\quad F$

F MPO expression
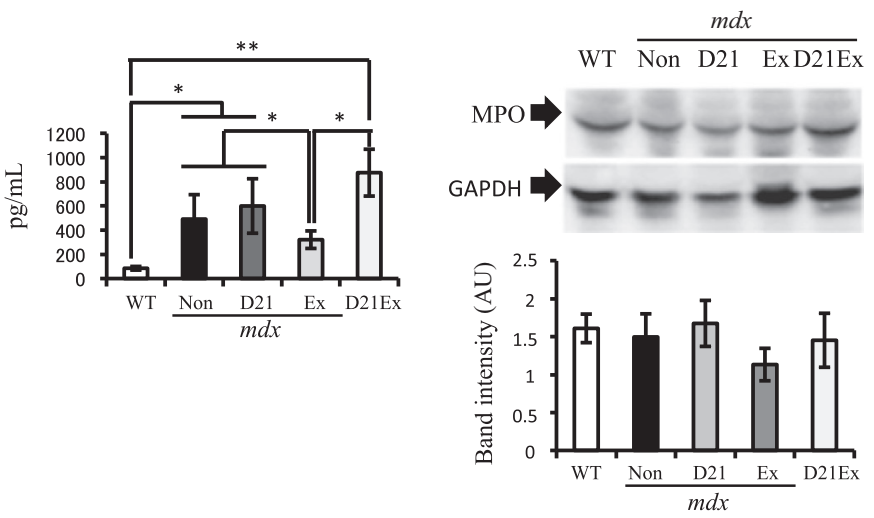

Figure 7 Differential cytokine and chemokine patterns in gastrocnemius muscle of $m d x$ mice treated with NOX-D21 and/or subjected to low-intensity training. Relative abundance of cytokines and chemokines in muscle lysates was quantified using the Proteome Profiler array. A: Array images. B: Cropped array images. C: Quantification of representative data presented in B. Expression profiles of IL-1RA and tissue inhibitor of metalloproteinases-1 (TIMP-1) were confirmed by Western blot (D) and enzyme-linked immunosorbent assay (E). Western blots were performed on the same membrane, but the positions of the bands D21 and Ex were interchanged. F: Expression of myeloperoxidase (MPO) was evaluated by Western blot and normalized to glyceraldehyde-3-phosphate dehydrogenase (GAPDH). Data are expressed as means $\pm \mathrm{SD}(\mathbf{C}-\mathbf{F}) .{ }^{*} P<0.05,{ }^{* *} P<0.01$ indicate a significant difference between two groups. AU, arbitrary unit; CCL2, chemokine ligand 2; Ex, exercised; GM-CSF, granulocyte-macrophage colony-stimulating factor; IFN- $\gamma$, interferon- $\gamma$; Non, nonexercised; TNF- $\alpha$, tumor necrosis factor- $\alpha$.

NOX-D21 alone increased IL-1RA expression above the levels of nonexercised and exercised $m d x$ mice. Also, the IL-RA level in muscles from treated-exercised mice was still higher compared with muscles from exercised ones (Figure 7, C and D). Finally, we analyzed the expression level of TIMP-1 by ELISA, and found a higher level in muscles of treated $m d x$ mice, as well as from treated-exercised ones, compared with exercised $m d x$ mice (Figure 7E).

\section{Discussion}

The results of our study show, for the first time, that LIT reduces the inflammatory status in skeletal muscle of $m d x$ 
mice. We hypothesized first that LIT would diminish immune cell populations as well as levels of cytokines and chemokines. We also reasoned that blockade of cytokine and chemokine action would rescue the $m d x$ phenotype.

In agreement with our first hypothesis, we found that levels of C5a, CCL2, and TIMP-1 were increased in $m d x$ skeletal muscle and that LIT lowered levels of CCL2 and TIMP-1. In parallel, populations of $\mathrm{CD}^{+} 8^{+} / \mathrm{F} 4 / 80^{+}$macrophages and inflammatory M1 macrophages were reduced in exercised $m d x$ muscle.

Furthermore, we found that inhibition of C5a by the L-aptamer NOX-D21 rescued the $m d x$ phenotype through a reduction of muscle damage and a shift to fast muscle fibers. Unexpectedly, NOX-D21-treated $m d x$ mice that exercised simultaneously showed increased muscle damage and a switch to slow muscle fibers. The main results are summarized in Figure 8.

\section{Inflammatory Status of Skeletal Muscle in Nonexercised $m d x$ Mice}

Muscles of $m d x$ mice are characterized by high levels of cytokines/chemokines and infiltration of immune cells. ${ }^{26}$ In agreement with previous studies, we observed an overexpression of CCL $2^{27}$ and TIMP- $1 .{ }^{28}$ We also report, for the first time, an overexpression of the complement cleavage product C5a (Figure 2). In contrast, levels of cytokines commonly associated with an inflammatory response in myopathies, such as IL-1 $\beta$, IL-6, transforming growth factor$\beta 1$, insulin-like growth factor 1 , or tumor necrosis factor- $\alpha,{ }^{1}$ remained stable. Similar results were reported in a study in which the same Proteome Profiler tool was used. ${ }^{2}$ Likely, cytokines released by the muscle itself, such as CCL2 and TIMP- $1,{ }^{29}$ are more prone to be detected in full muscle extracts than those secreted by macrophages. Still consistent with previous reports, a high concentration of $\mathrm{CD}^{+} 8^{+}$ cells $^{2,30}$ was observed in $m d x$ muscle (Figure 1). Previous immunohistochemical data suggest that the macrophage population shifted from the proinflammatory M1 type in the early phase of the pathology (4-week-old), to the regenerative M2 type during the late phase (12-week-old). ${ }^{8}$ Consistent with this report, we found increased levels of both M1 and M2 populations in muscles of 8-week-old $m d x$ mice.

Impact of Low-Intensity Training on the Inflammatory Status of Exercised $m d x$ Mice

We report herein, for the first time, that LIT of 4-week-old $m d x$ mice caused a decrease of CCL2 and TIMP-1 levels in their skeletal muscle (Figure 2). The monocyte chemoattracting protein-1 (CCL2) is one of the key chemokines that regulate the migration and the infiltration of monocytes/ macrophages. ${ }^{31}$ Thus, we expected a lower concentration of infiltrated immune cells in exercised $m d x$ muscle. In contrast, we found a higher amount of $\mathrm{CD}^{+} 8^{+}$cells (Figure 1), predominantly differentiated $\mathrm{F} 4 / 80^{+}$ macrophages (Figure 1C). Interestingly, within the macrophage population, the number of M1 macrophages was decreased (Figure 1B), whereas the one of M2 macrophages remained constant (Figure 1, A and B), leading to an increased M2/M1 ratio. As reported in our previous study ${ }^{16}$ and confirmed herein, LIT of $m d x$ mice caused an improvement of grip strength and of force/weight ratio (Figure 3). Taken together, these results suggest that LIT rescued the $m d x$ phenotype by increasing the quantity of macrophages and a shift from M1 to M2 macrophage populations.

\section{Cytokine/Chemokine Inhibition in $m d x$ Mice}

Because levels of CCL2, TIMP-1, and C5a were elevated in $m d x$ muscle (Figure 2), we assumed that their overexpression contributed to the increased inflammatory status in the dystrophic phenotype, such as in dystrophic mice or DMD patients. We excluded TIMP-1, which has been shown to be implied in remodeling of extracellular matrix, ${ }^{32}$ and focused on CCL2 and C5a for their role as chemotactic factors. ${ }^{31,33}$ Nonexercised and exercised $m d x$ mice were treated with inhibitors of CCL2 or C5a, the Spiegelmers mNOX-E36 and NOX-D21, respectively (Figure 3A), whereby $\mathrm{C} 5 \mathrm{a}$ inhibition led to higher physical ability of the mice, and CCL2 inhibition did not (Figure 3B). Therefore, we focused our further investigations on the inhibition of C5a.

\section{Impact of Inhibition of C5a on $m d x$ Muscle}

C5 is cleaved by the C5-convertase into C5a and C5b during the activation of the complement cascade. C5a acts as an anaphylatoxin, playing a critical role in enhancement of inflammation, ${ }^{33}$ whereas $\mathrm{C} 5 \mathrm{~b}$ binds to complement components $\mathrm{C} 6, \mathrm{C} 7, \mathrm{C} 8$, and $\mathrm{C} 9$ to form the membrane attack complex ring. ${ }^{34}$ Therapeutic blockage of C5 cleavage has been shown to rescue pathological states characterized by sterile tissue inflammation, such as myasthenia gravis ${ }^{35}$ and inflammatory myopathies. ${ }^{36}$ Furthermore, it has been shown that specific inhibition of C5a, while sparing C5b, with the Spiegelmer NOX-D20, of which NOX-D21 is a follow-up compound, was enough to improve the phenotype of a murine model of sepsis. ${ }^{37}$

C5a acts as a chemoattracting factor for cells of the myeloid lineage, ${ }^{24}$ such as mast cells, neutrophils, or the $\mathrm{CD} 8^{+}$monocytes and macrophages, whose numbers are increased in $m d x$ muscles (Figure 1). Four weeks of treatment with NOX-D21 improved the $m d x$ phenotype (Figure 3), reduced the number of necrotic fibers (Figure 4), and switched muscle fibers to the glycolytic fast type (Figure 5). We considered that the observed reduction of infiltrated $\mathrm{Ly}_{6 \mathrm{C}}^{+}$monocytes and neutrophils (Figure 6) could be the underlying reason for these beneficial effects, as it has been shown that depletion of neutrophils reduced necrosis in dystrophic muscles. ${ }^{38}$ However, immunoblot 
A

mdxmuscle

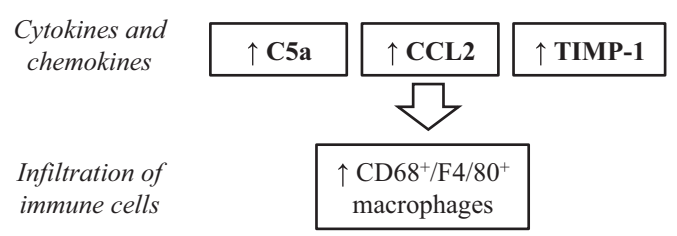

$\uparrow$ M1 macrophages $\left(\mathrm{iNOS}^{+}\right)$

$\uparrow \mathrm{M} 2$ macrophages $\left(\mathrm{CD} 163^{+}\right)$

B

+ LIT

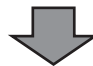

$=\mathbf{C 5 a}$
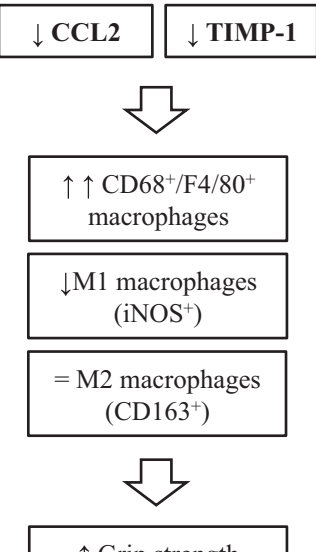

$\uparrow$ Grip strength
+ C5a inhibition
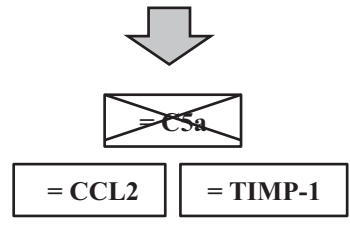

$\uparrow$ IL-1RA

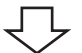

\section{$\uparrow \uparrow \mathrm{CD} 68^{+} / \mathrm{F} 4 / 80^{+}$} macrophages

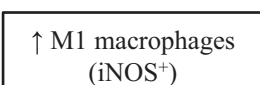
$\left(\mathrm{iNOS}^{+}\right)$

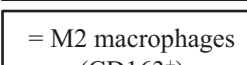
$\left(\mathrm{CD} 63^{+}\right)$

$+$
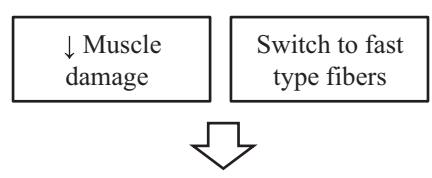

$\uparrow$ Grip strength
+ C5a inhibition and LIT
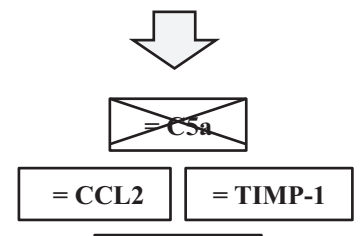

= IL-1RA

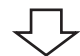

\section{$\uparrow \mathrm{CD}^{+} 8^{+} / \mathrm{F} 4 / 80$}

macrophages

$\uparrow$ M1 macrophages $\left(\mathrm{iNOS}^{+}\right)$

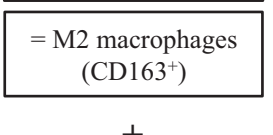

$+$
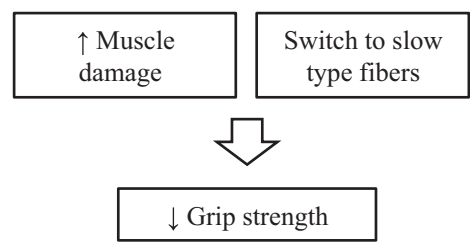

Figure 8 Graphical summary of the study. A: Changes in cytokine levels and immune cell populations in gastrocnemius muscle of $m d x$ mice compared with muscle wild-type mice. B: Changes in cytokine levels, immune cell populations, and muscle damage in gastrocnemius muscle of $m d x$ mice after low-intensity training (LIT) and/or treatment with the C5a complement inhibitor, compared with untreated $m d x$ mice. iNOS, inducible nitric oxide synthase.

analysis using the neutrophil marker myeloperoxidase was not supporting this hypothesis (Figure 7). Because C5a also attracts monocytes, we expected a lower amount of CD68 ${ }^{+}$ cells in muscle of treated $m d x$ mice. Yet, numbers of $\mathrm{CD} 68^{+} / \mathrm{F} 4 / 80^{+}$macrophages increased in these muscles. This could be because of proliferation of resident tissue macrophages. These cells represent a heterogeneous population of local immune cells, different from the circulating populations, which are produced by hematopoiesis. ${ }^{39}$ A recent study showed that depletion of circulating monocytes enhanced the proliferation of resident macrophages in skeletal muscle after injury. ${ }^{40}$ Thus, inhibition of C5a possibly reduced infiltration of circulating monocytes but stimulated the proliferation or differentiation of their local progenitors.

Finally, C5a inhibition increased the expression of the IL-1 receptor antagonist, IL1-RA. Previous studies showed that treatment with recombinant IL1-RA improved the grip strength of $m d x$ mice, ${ }^{41}$ which is in accordance with our results. Increased expression of IL1-RA in NOXD21-treated muscles appears paradoxical at first sight, because IL1-RA is mainly produced by neutrophils ${ }^{42}$ or M2 macrophages. ${ }^{43}$ However, a previous study showed that inhibition of another chemoattracting molecule, P-selectin, also leads to decreased neutrophil infiltration, increased numbers of macrophages, and increased 
expression of IL1-RA in nerve, which is consistent with our observations. ${ }^{44}$

\section{Impact of Inhibition of C5a on Exercised $m d x$ Muscle}

The phenotype of $m d x$ mice was improved after 4 weeks of LIT or treatment with NOX-D21. We assumed that exercise and C5a inhibition would act together to improve the quality of $m d x$ muscle. However, treated and exercised $m d x$ mice had lower grip strength (Figure 3), experienced muscle damage (Figure 4), and their muscles were switched toward the oxidative slow type (Figure 5). We expected that differences between treated, and treated and exercised $m d x$ mice would be reflected by a difference in immune cell population. However, numbers of $\mathrm{CD}^{+} 8^{+}$cells increased and the balance M1/M2 macrophages leaned in favor of the M1 type (Figure 6). The only difference observed was in the level of IL-1RA, which was slightly, but not significantly, higher in nonexercised NOX-D21-treated $m d x$ mice, compared to exercised treated ones. Thus, further investigations will be necessary to understand the reason for the discrepancy between LIT and C5a inhibition.

\section{Conclusion}

In this study, we have used immunoblotting, FACS, and immunochemistry to assess the effects of 4 weeks of LIT on expression of cytokine/chemokine levels and on populations of macrophages in gastrocnemius muscle of 8-week-old $m d x$ mice. We observed that the inflammatory mediators CCL2 and C5a were overexpressed, the number of CD68 ${ }^{+}$ monocytes/macrophages was increased, and that the macrophage population shifted to the proinflammatory M1 type. LIT reduced the expression of CCL2, increased the concentration of $\mathrm{CD} 68^{+} / \mathrm{F} 4 / 80^{+}$cells, and shifted the macrophage population to the regenerative M2 type. Furthermore, we demonstrated that inhibition of C5a complement rescued the $m d x$ phenotype, possibly by promoting IL-1RA expression, reducing muscle damage and switching muscle fibers toward the fast glycolytic type. However, simultaneous LIT and pharmacological C5a inhibition with NOX-D21 counteracted each other and led to a switch toward slow fiber type.

The present results reveal the effects of LIT on the inflammatory status of $m d x$ mice and suggest that NOX-D21 could become an anti-inflammatory drug for DMD patients.

\section{Acknowledgments}

We thank Drs. Yoshitsugu Aoki and Shouta Miyatake as well as the members of the Department of Molecular Therapy, National Institute of Neuroscience, National Center of Neurology and Psychiatry, for support and useful discussions; the members of the small animal facility, National Institute of Neuroscience, for technical assistance; and Benjamin Raveney (National Institute of Neuroscience) for discussions.

\section{Supplemental Data}

Supplemental material for this article can be found at http://dx.doi.org/10.1016/j.ajpath.2016.12.019.

\section{References}

1. Evans NP, Misyak SA, Robertson JL, Bassaganya-Riera J, Grange RW: Immune-mediated mechanisms potentially regulate the disease time-course of Duchenne muscular dystrophy and provide targets for therapeutic intervention. PM R 2009, 1:755-768

2. Nitahara-Kasahara Y, Hayashita-Kinoh H, Chiyo T, Nishiyama A, Okada H, Takeda S, Okada T: Dystrophic mdx mice develop severe cardiac and respiratory dysfunction following genetic ablation of the anti-inflammatory cytokine IL-10. Hum Mol Genet 2014, 23: 3990-4000

3. Spencer MJ, Walsh CM, Dorshkind KA, Rodriguez EM, Tidball JG: Myonuclear apoptosis in dystrophic mdx muscle occurs by perforinmediated cytotoxicity. J Clin Invest 1997, 99:2745-2751

4. Wehling M, Spencer MJ, Tidball JG: A nitric oxide synthase transgene ameliorates muscular dystrophy in mdx mice. J Cell Biol 2001, 155: $123-131$

5. Mojumdar K, Liang F, Giordano C, Lemaire C, Danialou G, Okazaki T, Bourdon J, Rafei M, Galipeau J, Divangahi M, Petrof BJ Inflammatory monocytes promote progression of Duchenne muscular dystrophy and can be therapeutically targeted via CCR2. EMBO Mol Med 2014, 6:1476-1492

6. Spencer MJ, Montecino-Rodriguez E, Dorshkind K, Tidball JG: Helper $\left(\mathrm{CD} 4^{+}\right)$and cytotoxic $\left(\mathrm{CD} 8^{+}\right) \mathrm{T}$ cells promote the pathology of dystrophin-deficient muscle. Clin Immunol 2001, 98:235-243

7. Martinez FO, Gordon S: The M1 and M2 paradigm of macrophage activation: time for reassessment. F1000Prime Rep 2014, 6:13

8. Villalta SA, Nguyen HX, Deng B, Gotoh T, Tidball JG: Shifts in macrophage phenotypes and macrophage competition for arginine metabolism affect the severity of muscle pathology in muscular dystrophy. Hum Mol Genet 2009, 18:482-496

9. Gleeson M, Bishop NC, Stensel DJ, Lindley MR, Mastana SS Nimmo MA: The anti-inflammatory effects of exercise: mechanisms and implications for the prevention and treatment of disease. Nat Rev Immunol 2011, 11:607-615

10. Alexanderson H: Physical exercise as a treatment for adult and juvenile myositis. J Intern Med 2016, 280:75-96

11. Kawanishi N, Yano H, Yokogawa Y, Suzuki K: Exercise training inhibits inflammation in adipose tissue via both suppression of macrophage infiltration and acceleration of phenotypic switching from M1 to M2 macrophages in high-fat-diet-induced obese mice. Exerc Immunol Rev 2010, 16:105-118

12. Hyzewicz J, Ruegg UT, Takeda S: Comparison of experimental protocols of physical exercise for $\mathrm{mdx}$ mice and Duchenne muscular dystrophy patients. J Neuromuscul Dis 2015, 2:325-342

13. Hayes A, Williams DA: Contractile function and low-intensity exercise effects of old dystrophic (mdx) mice. Am J Physiol 1998, 274(4 Pt 1): C1138-C1144

14. Baltgalvis KA, Call JA, Cochrane GD, Laker RC, Yan Z, Lowe DA Exercise training improves plantar flexor muscle function in $\mathrm{mdx}$ mice. Med Sci Sports Exerc 2012, 44:1671-1679

15. Call JA, McKeehen JN, Novotny SA, Lowe DA: Progressive resistance voluntary wheel running in the mdx mouse. Muscle Nerve 2010, $42: 871-880$

16. Hyzewicz J, Tanihata J, Kuraoka M, Ito N, Miyagoe-Suzuki Y, Takeda S: Low intensity training of mdx mice reduces carbonylation 
and increases expression levels of proteins involved in energy metabolism and muscle contraction. Free Radic Biol Med 2015, 82: 122-136

17. Radley-Crabb H, Terrill J, Shavlakadze T, Tonkin J, Arthur P, Grounds M: A single 30min treadmill exercise session is suitable for "proof-of concept studies" in adult mdx mice: a comparison of the early consequences of two different treadmill protocols. Neuromuscul Disord 2012, 22:170-182

18. Terrill JR, Radley-Crabb HG, Grounds MD, Arthur PG: $\mathrm{N}$-acetylcysteine treatment of dystrophic mdx mice results in protein thiol modifications and inhibition of exercise induced myofibre necrosis. Neuromuscul Disord 2012, 22:427-434

19. Pessina P, Cabrera D, Morales MG, Riquelme CA, Gutiérrez J, Serrano AL: Novel and optimized strategies for inducing fibrosis in vivo: focus on Duchenne muscular dystrophy. Skelet Muscle 2014, 4:7

20. Okano T, Yoshida K, Nakamura A, Sasazawa F, Oide T, Takeda S: Chronic exercise accelerates the degeneration-regeneration cycle and downregulates insulin-like growth factor-1 in muscle of mdx mice. Muscle Nerve 2005, 32:191-199

21. Aoki Y, Nakamura A, Yokota T, Saito T, Okazawa H, Nagata T, Takeda S: In-frame dystrophin following exon 51-skipping improves muscle pathology and function in the exon 52-deficient mdx mouse. Mol Ther 2010, 18:1995-2005

22. De Paepe B, De Bleecker JL: Cytokines and chemokines as regulators of skeletal muscle inflammation: presenting the case of Duchenne muscular dystrophy. Mediators Inflamm 2013, 2013:540370

23. Sun D, Zhang M, Liu G, Wu H, Zhu X, Zhou H, Shi M: Real-time imaging of interactions of neutrophils with Cryptococcus neoformans demonstrates a crucial role of complement C5a-C5aR signaling. Infect Immun 2015, 84:216-229

24. Guo RF, Ward PA: Role of C5a in inflammatory responses. Annu Rev Immunol 2005, 23:821-852

25. Yatime L, Maasch C, Hoehlig K, Klussmann S, Andersen GR, Vater A: Structural basis for the targeting of complement anaphylatoxin C5a using a mixed L-RNA/L-DNA aptamer. Nat Commun 2015, 6:6481

26. Spencer MJ, Tidball JG: Do immune cells promote the pathology of dystrophin-deficient myopathies? Neuromuscul Disord 2001, 11: $556-564$

27. Shireman PK, Contreras-Shannon V, Ochoa O, Karia BP, Michalek JE, McManus LM: MCP-1 deficiency causes altered inflammation with impaired skeletal muscle regeneration. J Leukoc Biol 2007, 81:775-785

28. von Moers A, Zwirner A, Reinhold A, Brückmann O, van Landeghem F, Stoltenburg-Didinger G, Schuppan D, Herbst H, Schuelke M: Increased mRNA expression of tissue inhibitors of metalloproteinase-1 and -2 in Duchenne muscular dystrophy. Acta Neuropathol 2005, 109:285-293

29. Johnson RW, White JD, Walker EC, Martin TJ, Sims NA: Myokines (muscle-derived cytokines and chemokines) including ciliary neurotrophic factor (CNTF) inhibit osteoblast differentiation. Bone 2014, 64:47-56

30. Li H, Mittal A, Makonchuk DY, Bhatnagar S, Kumar A: Matrix metalloproteinase-9 inhibition ameliorates pathogenesis and improves skeletal muscle regeneration in muscular dystrophy. Hum Mol Genet 2009, 18:2584-2598

31. Deshmane SL, Kremlev S, Amini S, Sawaya BE: Monocyte chemoattractant protein-1 (MCP-1): an overview. J Interferon Cytokine Res 2009, 29:313-326

32. Chen X, Li Y: Role of matrix metalloproteinases in skeletal muscle: migration, differentiation, regeneration and fibrosis. Cell Adh Migr 2009, 3:337-341

33. Klos A, Tenner AJ, Johswich KO, Ager RR, Reis ES, Köhl J: The role of the anaphylatoxins in health and disease. Mol Immunol 2009, 46: 2753-2766

34. Bubeck D: The making of a macromolecular machine: assembly of the membrane attack complex. Biochemistry 2014, 53:1908-1915

35. Huda R, Tüzün E, Christadoss P: Targeting complement system to treat myasthenia gravis. Rev Neurosci 2014, 25:575-583

36. Gordon PA, Winer JB, Hoogendijk JE, Choy EH: Immunosuppressant and immunomodulatory treatment for dermatomyositis and polymyositis. Cochrane Database Syst Rev 2012, 8:CD003643

37. Hoehlig K, Maasch C, Shushakova N, Buchner K, Huber-Lang M, Purschke WG, Vater A, Klussmann S: A novel C5a-neutralizing mirror-image (1-)aptamer prevents organ failure and improves survival in experimental sepsis. Mol Ther 2013, 21:2236-2246

38. Hodgetts S, Radley H, Davies M, Grounds MD: Reduced necrosis of dystrophic muscle by depletion of host neutrophils, or blocking TNFalpha function with Etanercept in mdx mice. Neuromuscul Disord 2006, 16:591-602

39. Davies LC, Taylor PR: Tissue-resident macrophages: then and now. Immunology 2015, 144:541-548

40. Côté CH, Bouchard P, van Rooijen N, Marsolais D, Duchesne E: Monocyte depletion increases local proliferation of macrophage subsets after skeletal muscle injury. BMC Musculoskelet Disord 2013, 14:359

41. Benny Klimek ME, Sali A, Rayavarapu S, Van der Meulen JH, Nagaraju K: Effect of the IL-1 receptor antagonist kineret on disease phenotype in mdx mice. PLoS One 2016, 11:e0155944

42. McColl SR, Paquin R, Ménard C, Beaulieu AD: Human neutrophils produce high levels of the interleukin 1 receptor antagonist in response to granulocyte/macrophage colony-stimulating factor and tumor necrosis factor alpha. J Exp Med 1992, 176:593-598

43. Sica A, Mantovani A: Macrophage plasticity and polarization: in vivo veritas. J Clin Invest 2012, 122:787-795

44. Liou JT, Lee CM, Lin YC, Chen CY, Liao CC, Lee HC, Day YJ: $\mathrm{P}$-selectin is required for neutrophils and macrophage infiltration into injured site and contributes to generation of behavioral hypersensitivity following peripheral nerve injury in mice. Pain 2013, 154: 2150-2159 